University of Louisville

ThinkIR: The University of Louisville's Institutional Repository

Electronic Theses and Dissertations

$5-2017$

\title{
The sources of behavioral reinforcement : an examination of nonsocial reinforcement theory.
}

Heather Tolle

University of Louisville

Follow this and additional works at: https://ir.library.louisville.edu/etd

Part of the Criminology Commons, and the Criminology and Criminal Justice Commons

\section{Recommended Citation}

Tolle, Heather, "The sources of behavioral reinforcement : an examination of nonsocial reinforcement theory." (2017). Electronic Theses and Dissertations. Paper 2627.

https://doi.org/10.18297/etd/2627

This Doctoral Dissertation is brought to you for free and open access by ThinkIR: The University of Louisville's Institutional Repository. It has been accepted for inclusion in Electronic Theses and Dissertations by an authorized administrator of ThinkIR: The University of Louisville's Institutional Repository. This title appears here courtesy of the author, who has retained all other copyrights. For more information, please contact thinkir@louisville.edu. 
THE SOURCES OF BEHAVIORAL REINFORCEMENT: AN EXAMINATION OF NONSOCIAL REINFORCEMENT THEORY

\author{
By \\ Heather Tolle \\ B.A., University of Louisville, 2005 \\ M.A., University of Louisville 2007 \\ A Dissertation \\ submitted to the faculty of the \\ College of Arts and Sciences of the University of Louisville \\ in Partial Fulfillment of the Requirements \\ for the Degree of \\ Doctor of Philosophy in Criminal Justice \\ Department of Criminal Justice \\ University of Louisville \\ Louisville, Kentucky
}

May 2017 

THE SOURCES OF BEHAVIORAL REINFORCEMENT: AN EXAMINATION OF NONSOCIAL REINFORCEMENT THEORY

\author{
By \\ Heather Tolle \\ B.A., University of Louisville, 2005 \\ M.A., University of Louisville 2007 \\ A Dissertation Approved on
}

April 27, 2017

By the following Dissertation Committee:

\begin{tabular}{c}
\hline Dissertation Director \\
Dr. George E. Higgins \\
\hline Dr. Gennaro F. Vito \\
\hline Dr. Cherie Dawson-Edwards
\end{tabular}

Dr. Cherie Dawson-Edwards

Dr. Seana Golder 


\section{DEDICATION}

This dissertation is dedicated to my loving and infinitely patient husband, Nicholas Tolle. Without his love, support, and encouragement to chase my dreams, I would never push myself to continually grow. To my sister, Crystal, thanks for the sibling rivalry that pushes me to be better than you, and now my name is Dr. Spam, thank you. To my parents, thanks for instilling in me the importance of education.

To my NRN core team — thanks for always being my cheerleader, Alice. Thanks for doing my work for me, Jeremy, and thanks for taking ownership of the NRN, Kim, the NRN is your baby now, hope you love it like I have. Thanks to Trey, the best work

husband a girl could ask for in a job with no supervision. I could never have finished this endeavor without help from all of you guys. 


\section{ACKNOWLEDGEMENTS}

I would like to thank my dissertation chair, Dr. George Higgins, for his continually help and guidance through this process. Without his patience and continually explaining the statistics, I could not have made it this far. I would also like to thank Dr. Gennaro Vito for his encouragement and support. I would like to thank Dr. Cherie Dawson-Edwards for agreeing to be on my dissertation committee and the valuable insight provided on the

project. Finally, I'd like to thank Dr. Seana Golder for her continual encouragement and support of this dissertation and its real-world applications. 


\title{
ABSTRACT \\ THE SOURCES OF BEHAVIORAL REINFORCEMENT: AN EXAMINATION OF NONSOCIAL REINFORCEMENT THEORY
}

\author{
Heather Tolle
}

April 27, 2017

This dissertation attempts to gain a better understanding of the means by which deviant behavior is perpetuated. Nonsocial reinforcement theory proposes that behavior is reinforced by psychological, physiological, and social rewards of the behavior. This reinforcement of the behavior causes the frequency of the behavior to increase. Specifically, when an individual uses marijuana, the psychological and physiological rewards gained from the behavior can lead the individual to continue using marijuana over time. This dissertation will test this reciprocal impact of increased psychological and physiological responses leading to an increase in the behavior. Data from the National Longitudinal Study of Youth Children and Young Adults Survey (NLSY79 Child) was utilized from years 1996 and 1999. The sample was filtered to only those individuals between the ages of 14 and 20 during the 1996 year. Measurements of marijuana use, risk taking as a means of physiological rewards, and self-esteem as a measure of psychological rewards were examined during both years along with demographic factors of sex, age, race, and socioeconomic status. Structural equation 
modeling was used to test the longitudinal model of nonsocial reinforcement theory. Findings from the first wave of data collection suggest that individuals with a higher preference for risk taking are more likely to use marijuana. Findings from the second wave show a relationship between low self-esteem and high risk taking. The longitudinal reciprocal effects were not supported in the current analysis. The two-year time frame utilized in the study may be too long to examine the reciprocal effects. Regardless, the impact of self-esteem and risk taking propensity in influencing behavior can be utilized in interventions to help reduce deviant behavior. The additional information learned about how behavior is reinforced can be used to create new and innovative interventions to break the cycle of reinforcement and reduce marijuana use. 


\section{TABLE OF CONTENTS}

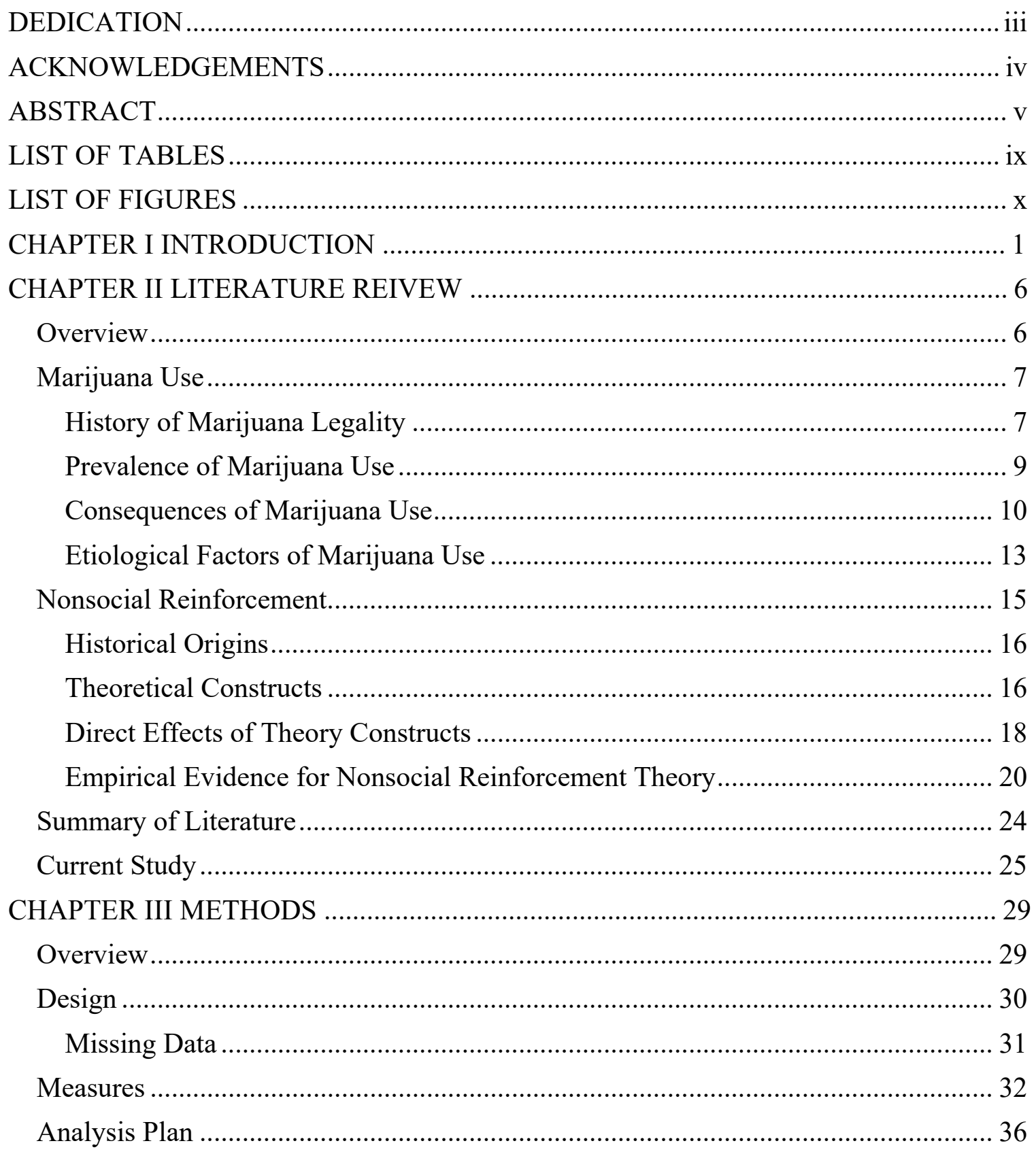




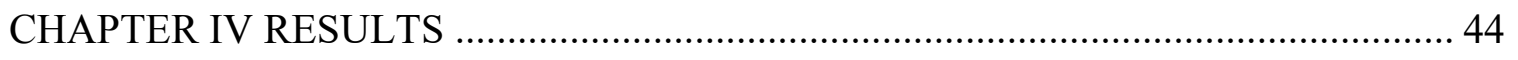

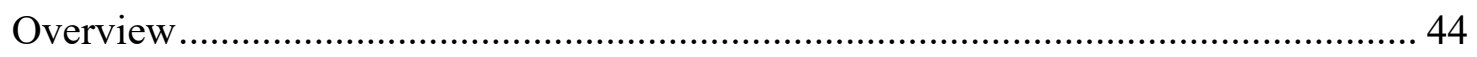

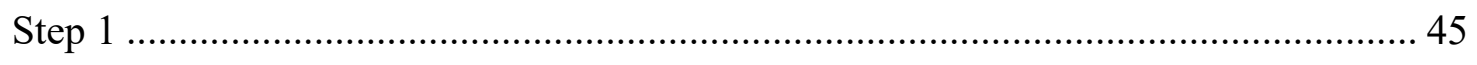

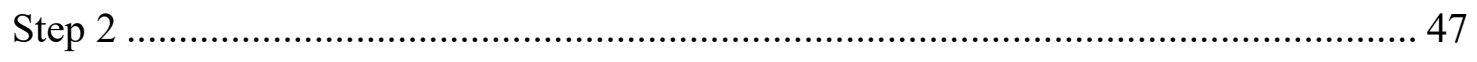

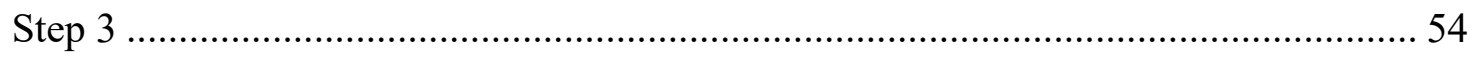

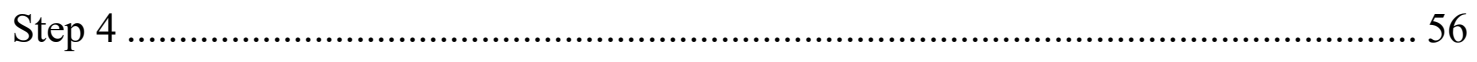

Step 5

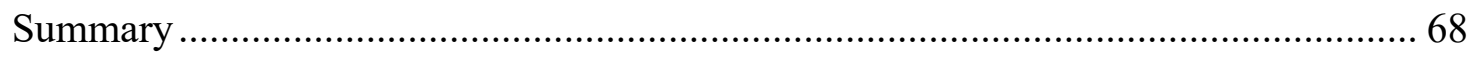

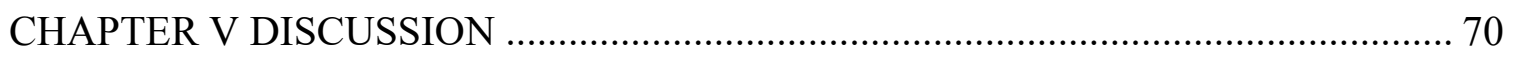

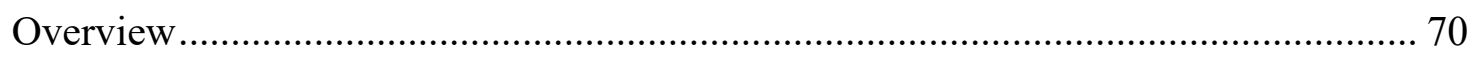

Implications for Nonsocial Reinforcement Theory ................................................ 71

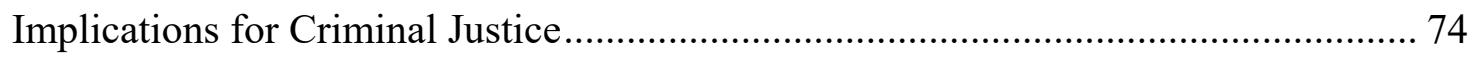

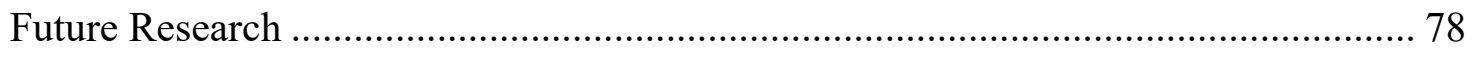

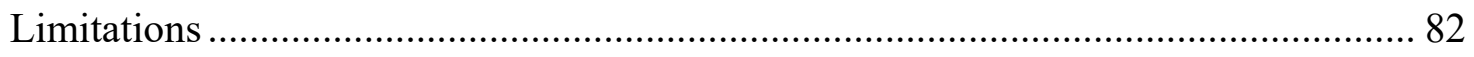

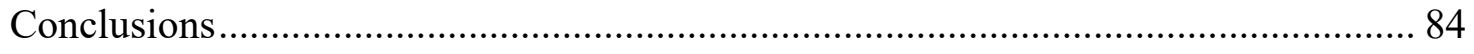

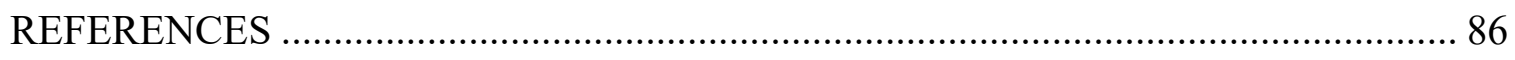

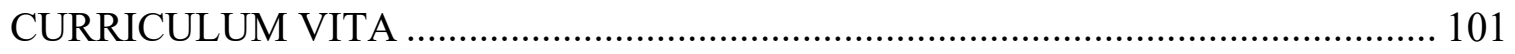




\section{LIST OF TABLES}

TABLE

PAGE

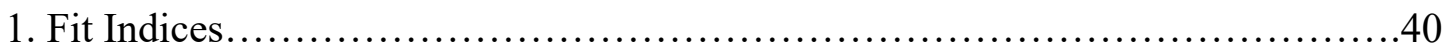

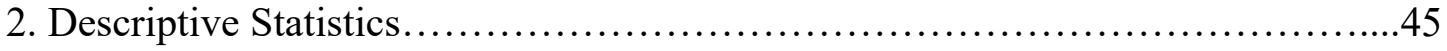

3. Correlation Coefficients..................................................... 48

4. Confirmatory Factor Analysis Factor Loadings ................................54

5. Cross-sectional Structural Model Analysis....................................56

6. Indirect relationships in Cross-sectional Models..............................58

7. Modified Longitudinal Structural Model Analysis...............................61

8. Indirect Relationships of Nonsocial Reinforcement...........................63 


\section{LIST OF FIGURES}

FIGURE

PAGE

1. Reciprocal Effects Model...............................................26

2. Confirmatory Factory Analysis........................................ 38

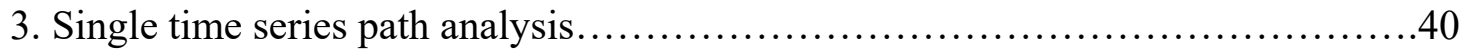

1. Longitudinal reciprocal effects......................................42

5. Modified Reciprocal Relationship Model.................................60

6. Modified Reciprocal Relationship Model with standardized coefficients..........65 


\section{CHAPTER I}

\section{INTRODUCTION}

Marijuana has been the most frequently abused illegal substance in the United States, particularly among adolescents and young adults. Use and abuse of the substance has remained high over the years (Center for Behavioral Health Statistics and Quality, 2015). Nearly $81 \%$ of those using an illegal drug were using marijuana, and most (65\%) were using marijuana exclusively (Substance Abuse and Mental Health Services Administration, 2014). Marijuana arrests accounted for $42.6 \%$ of all drug-related arrests in the US in 2005 (Common Sense for Drug Policy, 2007). The federal cost of attempts at disrupting the marijuana drug trade has been estimated at $\$ 2.6$ billion per year. Police, judicial and corrections expenses related to marijuana prohibition account for nearly $\$ 5.1$ billion of federal and state funds (Miron, 2005). The large expense of enforcing federal prohibition laws and the continually increasing use of marijuana necessitates novel approaches to interventions for cessation and abstinence from marijuana use.

In 1970, the Controlled Substance Act was passed by congress which divided controlled substances into five different categories, or schedules based on the drug's potential for abuse, addictive qualities, and medical utility (Drug Enforcement Administration, n.d.). Marijuana has been classified as a Schedule I controlled substance indicating it has no medicinal value and a large potential for abuse. Other drugs in this 
category are heroin, ecstasy, and LSD (See Khatapoush and Hallfors, 2004 for a review of marijuana legislation in the US).

Use of marijuana has been connected to many negative outcomes. Immediate physiological impacts from marijuana use include impaired driving while under the influence (Rogeberg \& Elvik, 2016) and impairments in learning and memory (Grant, Gonzalez, Carey, Natarajan, \& Wolfson, 2003). Long term use can lead to increased risk of lung cancer and other health risks (Imtiaz et al., 2016). Marijuana use has also been associated with negative social outcomes such as lower educational levels, less participation in social activities that don't include drug use, and fewer non-drug using relationships (Meshesha, Dennhardt, \& Murphy, 2015; Patton et al., 2007). A connection has been found between marijuana use and higher rates of deviant behavior (Derzon \& Lipsey, 1999; Moore, Stuart, \& Meehan, 2008; Patton et al., 2007). Despite our knowledge of the consequences of marijuana use, increasing prevalence statistics indicate that interventions to reduce or prevent marijuana use may not have been effective (Azofeifa et al., 2016). More research is needed to determine the factors influencing decisions to use marijuana, which can then be translated into better formulated interventions to reduce use and prevent the negative consequences of use.

Various criminological theories have been utilized in an effort to increase our understanding of the motivating factors that lead to marijuana use. Learning theories have provided strong evidence of the causal mechanisms in which behavior is learned (Akers \& Jensen, 2006; Akers, Krohn, Lanza-Kaduce, \& Radosevich, 1979; Pratt et al., 2010). Differential association theory as proposed by Sutherland (1947) argued that individuals learn deviant behavior in the same way any other behavior is learned. 
Burgess and Akers (1966) reformulated differential association theory to improve the testability of the theory and proposed that we learn behavior through others, who then reinforce this behavior. Akers (1985) further expanded on the theory and proposed social learning theory. Social learning theory suggests that all behavior is learned, including criminal behavior, through reinforcement. Akers focused mostly on the social reinforcement of behavior stating that nonsocial reinforcement would be limited to the physiological realm rather than behavioral (Akers, 1994). Despite Akers' (1994) view, Wood, Gove, Wilson, and Cochran (1997) have made a convincing case for the reinforcing nature of nonsocial rewards in their Nonsocial Reinforcement Theory.

Wood et al. (1997) proposed that habitual behavior is reinforced not just by social rewards proposed by Akers (1985), but also by nonsocial means of internal psychological and physiological rewards. Physiological reinforcement of behavior is derived from an individual's preferences for sensation seeking and risk taking drives that are unique to each individual. Some individuals derive more enjoyment from risky situations than others. This enjoyment is an internal reward for the performance of behavior, leading to an increase in risky behavior (Wood et al., 1997). Wood and colleagues (1997) nonsocial reinforcement theory based psychological reinforcement of behavior on the internal meaning and positive psychological connections the individual feels after the behavior. Some individuals may have their sense of identity connected to their commission of crimes, hence commission of crimes will give a boost to the individual's psychological well-being, or self-esteem, rewarding the behavior and increasing the likelihood of the behavior in the individual (Wood et al., 1997). 
While Nonsocial Reinforcement Theory has yet to be fully tested, the literature on the theory has been growing, and supporting the idea that nonsocial reinforcement has a great influence on behavior (Brezina \& Topalli, 2012; Cooper, May, Soderstrom, \& Jarjoura, 2009; Higgins, Jennings, Marcum, Ricketts, \& Mahoney, 2011; Higgins, Mahoney, \& Ricketts, 2009; Jarjoura \& May, 2000; May, 2003; Schaefer, 2016; Stevens, May, Rice, \& Jarjoura, 2011; Wood et al., 1997). Additionally, there have been numerous studies examining the connection between deviant behavior and risk-taking or sensation seeking (Brezina \& Aragones, 2004; Romer \& Hennessy, 2007; Ruedy, Moore, Gino, \& Schweitzer, 2013; Wood, Cochran, Pfefferbaum, \& Arneklev, 1995; Wood, Pfefferbaum, \& Arneklev, 1993), supporting the influence of physiological rewards on behavior proposed by nonsocial reinforcement theory.

The inclusion of nonsocial reinforcement elements as an explanation for how behavior is learned and perpetuated gives a more complete picture of the influences on behavior. The reciprocal loop proposed by Wood and colleagues (1997) whereby the psychological and physiological rewards of the behavior contribute to its continuation has not yet been empirically tested. This dissertation tests the reciprocal loop suggested by nonsocial reinforcement theory. A confirmation of the influence of reinforcement from psychological and physiological rewards of a behavior would lead to a better understanding of behavioral choices. The increased understand can provide a new avenue for interventions for deviance avoidance and cessation. In order to test this theory, data will be analyzed from the National Longitudinal Survey of Youth 1979 Child and Young Adult Survey. The longitudinal survey followed the children of the women surveyed in the National Longitudinal Survey of Youth 1979. The use of this 
longitudinal data set will allow for the examination of physiological rewards, psychological rewards, and marijuana use at multiple time points. This analysis will provide an examination of the reciprocal effects of the nonsocial reinforcement of marijuana use as proposed by Wood and colleagues (1997).

This dissertation is organized in several chapters in order to test the above hypothesis. Chapter two will give a detailed account of the extant literature on marijuana use and nonsocial reinforcement. The chapter will discuss how nonsocial reinforcement can be used generate a better predictor of continual marijuana use. Chapter three will discuss the methodology used to test the hypotheses proposed in chapter two. Chapter four will give detailed results of the hypotheses tested using the methodology detailed in chapter three. Chapter five discusses the implications of the findings from chapter four, how it relates to the extant literature in chapter two, and how this new information can be used in interventions to reduce marijuana use. 


\section{CHAPTER II}

\section{LITERATURE REIVEW}

\section{Overview}

Previous research has been conducted on factors associated with marijuana use and nonsocial reinforcement, yet no study has examined the reinforcement over time as suggested to exist based on the theory. A thorough exploration of the extant literature is provided below. First, the marijuana literature is examined to understand the dangers of marijuana use and the factors contributing to individual use. Next, the literate on nonsocial reinforcement is reviewed examining how the theory was derived, verifying the empirical evidence supporting the theory's ability to explain behavior. Additionally, the individual elements of nonsocial reinforcement, risk taking and self-esteem, are examined for their direct influence on behavior. An examination of previous findings is necessary in order to establish the current state of understanding on these topics and support the logic behind the proposed hypothesis. An understanding of previous literature will support the premise of the current study, and can lead to better interventions to reduce marijuana use and other deviant behavior. 


\section{Marijuana Use}

A more complete understanding of marijuana use is achieved through a thorough examination of the literature. First, an examination of the prevalence of use of marijuana establishes how widespread and common marijuana use is in the country. Second, the physiological and social consequences of marijuana use are examined. Next, literature examining the risk factors associated with marijuana use are discussed, specifically centered around the influence of peers, parents, the immediate situation, and internal factors in the individual that motivate marijuana use. The literature available on marijuana use will give a depth of understanding to the issues surrounding marijuana use.

\section{History of Marijuana Legality}

In the U.S., marijuana was first made illegal in 1937 with the passing the Marijuana Tax Act, which restricted and heavily taxed the sale and possession of marijuana (Millhorn, 2009). The Act was written by Harry J. Anslinger, the commissioner of the Bureau of Narcotics, as a result of a call from the newspaper industry, citizens, and legislators over inflated concerns about the drug (Inciardi, 2002). Job shortages during the Great Depression of the 1920's fueled racism and accusations that minorities, especially Mexicans, were taking American jobs (Moran, 2010). This led to the rejection of Mexican culture, which included the use of marijuana. Bogus claims such as Mexicans offering marijuana to children (Moran, 2010), African Americans on marijuana seducing white girls (Bender, 2016) and marijuana fueled homicidal rage (Inciardi, 2002). National fearmongering about marijuana use began when the government cut Anslinger's Bureau of Narcotics funding. Anslinger attributed much of 
the crime in the country to minorities under the influence of marijuana, linking minorities, crime, and marijuana in the public eye, paving the way for the passage of the Marijuana Tax Act (Moran, 2010).

There is evidence that the subsequent scheduling of marijuana in the Controlled Substances Act of 1970 was motivated by fears of cultural change. During this time the stereotypical marijuana user was conceptualized as a white college student rebelling against traditions. In an effort to maintain the status quo, politicians ran on platforms criticizing the ideology of the younger generation, which included a tough on marijuana stance. This allowed for the social acceptance of Schedule I status of marijuana, despite marijuana not meeting the criteria of being highly addictive or not having a medicinal use (Inciardi, 2002; Moran, 2010).

While marijuana remains a Schedule I drug based on the federal Control Substances Act, in recent years there has been a trend of decriminalization and legalization of marijuana at the state level. The legalization efforts can be a reflection of the growing social perception that marijuana is not as harmful as previously suggested. While the political rhetoric surrounding the dangers of marijuana may have changed, there are still some risks associated with marijuana use. Due to its classification as a federal crime, marijuana use is still a valid measure of deviant behavior. The current dissertation examines marijuana as it is illegal at the federal level and an indication of deviant behavior with a high enough frequency of occurrence to examine statistically with realistic sample sizes of the population. 


\section{Prevalence of Marijuana Use}

Marijuana is the most used illicit substance in the United States, and its use has been on the rise for more than a decade (Center for Behavioral Health Statistics and Quality, 2015). Marijuana is a plant that has psychoactive properties when smoked or ingested. THC, the psychoactive substance in marijuana, enters the brain and reacts with cannabinoid receptors in the brain which can cause feelings of euphoria, relaxation, disinhibition, increased sociability, and also nausea, dry mouth, dizziness, and impaired judgment (Drug Enforcement Administration, 2015).

Young adults between and 18 and 25 years old consistently have the highest rates of self-reported marijuana use, operationalized as use at least once in the last month (Center for Behavioral Health Statistics and Quality, 2015). The young adult age group also has the highest incidents of marijuana use disorder of any age group (Center for Behavioral Health Statistics and Quality, 2015). The number of individuals ever using marijuana at least once has continued to increase. Estimates show that of an average of 7,000 people per day over the age of 12 tried marijuana for the first time in 2014 (Azofeifa et al., 2016). Additionally, the perceived risks of smoking marijuana among those 12 years old or older has decreased, suggesting that individuals feel that there are fewer risks and consequences associated with marijuana use (Center for Behavioral Health Statistics and Quality, 2015). Longitudinal survey data shows that respondents report that the ability to obtain marijuana is getting easier over time (Azofeifa et al., 2016). 


\section{Consequences of Marijuana Use}

Numerous negative consequences have been linked to the use of marijuana. Immediate effects of marijuana use on the body leads to impaired driving ability. A positive correlation has been found between marijuana use and risk of driving while under the influence, indicating that individuals who use marijuana more often are more likely to also drive while under the influence (Rogeberg \& Elvik, 2016). Impairments in learning and issues with forgetting information have been identified in chronic marijuana smokers (Grant et al., 2003). Excessive use of marijuana in current users has been associated with lower IQ scores (Fried, Watkinson, James, \& Gray, 2002). Heavy marijuana users (those who use nearly every day) performed worse on tasks involving attention and planning than light marijuana users (using an average of once a month), which could be the result of marijuana remaining in the system, or the influence of withdraw from the drug (Pope \& Yurgelun-Todd, 1996).

Use of marijuana in early adolescence has been associated with impairments in attention and reaction times in later adolescence (Ehrenreich et al., 1999). The study examined the differences between marijuana users and non-users and found that those who started using marijuana at an early age had a more difficult time maintaining attention and had slower reaction times. The findings suggest that early adolescent marijuana use impairs brain development which was manifested in impairments in reaction time and attention span (Ehrenreich et al., 1999). Long term use of marijuana has been associated with negative physiological conditions such as lung cancer and schizophrenia triggered by extensive marijuana use (Imtiaz et al., 2016). Utilizing life expectancy estimates, calculations were performed based on the age and number of 
adverse life-altering events attributed to marijuana use. Factoring in issues of traffic fatalities, lung cancer, cannabis use disorder, and schizophrenia associated with marijuana use have resulted in 55,800 years lost to disability in 2012, and a total of 287 deaths in Canada (Imtiaz et al., 2016).

Marijuana use has also been connected to numerous negative social outcomes. Patton et al. (2007) found that heavy marijuana use during adolescence was associated with lower education levels, lack of being in a relationship, and parenthood at younger ages. Meshesha et al. (2015) found that students who used marijuana more frequently were less likely to participate in social activities that did not involve substance use, and were less likely to spend time studying or doing homework. Brook, Balka and Whiteman (1999) found that those using marijuana in early adolescence were at a higher risk in later adolescence for negative life consequences such as not graduating from high school, having multiple sexual partners, being less likely to use a condom, having more friends engaged in deviant behavior, and not perceiving drugs as being harmful. Similarly, Fergusson and Horwood (1997) found that in a New Zealand sample, those using marijuana before the age of 16 had higher rates of substance use, higher rates of juvenile offending, higher rates of unemployment, higher rates of mental health problems, and higher rates of school dropout at age 18 .

A review of the literature examining the relationship between marijuana use and academic achievement found that while many studies found an association between the two, the causality or spurious nature of the relationship is unclear (Lynskey \& Hall, 2000). Marijuana may lead to low academic achievement due to deficits in cognitive function, or due to a lack of motivation often associated with marijuana use. Low 
academic ability may drive an individual to use marijuana as a means of coping with the stress of poor academic performance. Additionally, the relationship may also be spurious as environmental factors could influence both marijuana use and academic achievement (Lynskey \& Hall, 2000).

Use of marijuana, while a deviant behavior itself, has been found to be connected to other forms of deviance. A meta-analysis examining how marijuana use can lead to other forms of delinquent behavior found evidence for a connection between marijuana use and concurrent deviance, yet a trajectory from early marijuana use to later deviant behavior was not supported. The study did find a connection between previous deviance and future use of marijuana, indicating that those youths who were more inclined to behave deviantly were also more inclined to use marijuana in the future (Derzon \& Lipsey, 1999). A longitudinal study of marijuana use in adolescence found that youths using marijuana at least weekly on more than two occasions were at a higher risk for using other drugs such as amphetamines, ecstasy, cocaine, or cigarette smoking, and not being in a relationship (Patton et al., 2007). Moore and colleagues (2008) found a connection between marijuana use and intimate partner aggression. While marijuana has traditionally not been associated with aggression, the study found that the withdraw effects from marijuana may influence intimate partner aggression associated with marijuana use (Moore et al., 2008).

Thus far, this dissertation has demonstrated that marijuana use is prevalent, especially among adolescents and early adults. Negative physiological and social consequences associated with marijuana use warrant interventions to reduce use. In order to reduce marijuana use, it is important to understand the factors that contribute to 
marijuana use. Existing literature exploring the possible paths leading to marijuana use are detailed below.

\section{Etiological Factors of Marijuana Use}

Beyond the outcomes associated with marijuana use, there has been a vast amount of research assessing the etiological factors of marijuana use. Empirical evidence for the role of peers in marijuana use has been well established. The friends an individual chooses to associate with influences individual drug use through their own use (Dishion, Capaldi, Spracklen, \& Li, 1995; Schaefer, Haas, \& Bishop, 2012), and pressuring the individual into using (Hays \& Ellickson, 1990). Peers substance use also has been found to inadvertently influence an individual by making the individual think that the likelihood of being caught is reduced as peers have not experienced consequences of being caught (Burkett \& Jensen, 1975).

Peer relations have been found to mediate the relationship between drug use and several factors commonly believed to influence drug use. For example, Burkett and Warren (1987) found that peer associations mediated the relationship between marijuana use and religiosity. Several studies have also found evidence of peer influences mediating the buffering effect of parental influence on drug use (Dishion et al., 1995). Even if an individual's parents were drug users or had pro-drug perspectives, peer influences were still able to mediate the parent and drug use relationship (Johnson, Marcos, \& Bahr, 1987). Peers acceptance of marijuana use was found to create a social environment in which marijuana use is an acceptable behavior and allowed for its use to 
be normalized (Malmberg et al., 2012; Walker, Neighbors, Rodriguez, Stephens, \& Roffman, 2011) $)^{1}$

Parental influences have also been found to play a role in adolescent substance use. Li, Pentz, and Chou (2002) found that parental substance use moderated the connection between peer and adolescent use. Galliher, Evans, and Weiser (2007) found that parental influence was able to predict the ability of an adolescent to resist substance use. Hence it is clear that both parental and peer influence have a great impact on adolescent substance use.

Structural factors present in the college environment have been found to be related to substance use. Schools with lower socioeconomic status and with less racial heterogeneity were associated with higher use of marijuana and other substances (Whaley, Smith, \& Hayes-Smith, 2011). These structural factors may create a social environment which influences more students to use marijuana. Factors present in the immediate environment the first time an individual is offered or has the opportunity to try an illicit substance may influence the decision to use. A study examining the use of prescription drugs for non-medical use found that the immediate circumstances play a large role in the decision-making processes. The amount of exposure, the motivation to use, and the access an individual has to the substance were major influences on the decision to use (Mui, Sales, \& Murphy, 2013). These findings could be generalized to marijuana use, yet more research is needed to determine the factors influencing marijuana use.

\footnotetext{
${ }^{1}$ While peer associations may be an important factor in marijuana use, in order to test the less-examined influences of psychological and social rewards, this dissertation will not test social rewards.
} 
Beyond the social and situational influences to use, there are many internal factors that have been associated with marijuana and other substance use in previous research. Self-devaluation has been found to lead an individual to find new ways to improve his or her self-perspective, which can include substance use (Kaplan, Martin, \& Robbins, 1984). Additionally, a bottom-up approach to determine the motivating factors for marijuana use by Blevins, Banes, Stephens, Walker, and Roffman (2016) found that one motivating factor for use is to relieve stress. The use of marijuana to relieve the internal negative emotions caused by stress is also in line with literature on alcohol use (Blevins et al., 2016). Another internal factor that has been found to be associated with substance use is a drive to stimulate the senses with novel and more extreme sensations. This sensation seeking drive has been found to associate with drug use (Byrnes, Miller, \& Schafer, 1999; Romer \& Hennessy, 2007; Wood, et al., 1995).

More research is needed on the etiology and habitual use of marijuana to better understand the factors influencing marijuana use. This increased understanding can lead to improved interventions to help resist marijuana use and to desist after dangerous patterns have been established. A better understanding of the behavior of marijuana use could be gained through a better understanding of how behavior in general is perpetuated or subsided by nonsocial reinforcement.

\section{Nonsocial Reinforcement}

Nonsocial reinforcement, as proposed by Wood and colleagues (1997) has been advanced as a means of explaining behavior. Before applying this theory as an explanation for marijuana use, a better understanding of the theory is necessary. First the 
historical origins of the theory are explored, followed by a detailed explanation of the theoretical constructs. Next, studies examining the direct effects of psychological and physiological rewards on behavior are explored. Finally, empirical evidence supporting the theory as an explanation of behavior is provided. This literature will support the use of nonsocial reinforcement as an explanation for behavior in general, and marijuana use specifically. Wood et al.'s (1997) theory of the reciprocal reinforcing relationships between behavior and physiological and psychological rewards has not been tested.

\section{Historical Origins}

Akers $(1985,1998)$ social learning theory proposed that operant conditioning and reinforcement were the means in which we learn behavior. Akers acknowledged that reinforcement can be both social and physiological, yet Akers asserted that the social influences had a stronger impact on behavior. Tests of Social Learning Theory in the literature have been almost exclusively done with an emphasis on social perpetuators of behavior, ignoring any other influence on behavioral learning. Recently, there has been some evidence suggesting that social reinforcement is not the only form of reinforcement that can be used to explain behavior. Wood et al. (1995) and Wood et al. (1997) proposed that reinforcement of behavior was based not only on social rewards, but also nonsocial rewards relating to psychological and physiological reinforcement of behavior.

\section{Theoretical Constructs}

In Wood and colleagues' (1997) nonsocial reinforcement theory, habitual involvement in crime and deviance are the result of rewards obtained from the behavior. 
Etiological factors that contribute to crime such as the personality of the individual and structural factors of the individual's environment are mediated through the influences of psychological, physiological, and social rewards. Deviant behavior is perpetuated in a loop of reinforcement between three sources of rewards. Rewards from behavior have been classified by Wood and colleagues (1997) as material and social rewards (termed exogenous rewards), psychological rewards (such as an increase in self-esteem), and physiological rewards (such as the enjoyment of risk taking).

Wood et al. (1997) based the theory of nonsocial reinforcement on the ideas of edgework and arousal theory. Edgework refers to any thrill-seeking behavior that poses a risk to the individual's wellbeing, such a skydiving or drug use. This risky behavior is often described by individuals performing the behavior as a calculated risk that poses a reduced risk to them due to their experience with the activity. Edgework involves walking the line between life and death at the extreme, flirting with disaster (Lyng, 1990). This thrill-seeking is a drive in all of us to varying degrees and can be a reinforcing reward on its own. Several studies have found a connection between crime or immoral behavior and positive feelings (Brezina \& Aragones, 2004; Romer \& Hennessy, 2007; Ruedy et al., 2013; Schaefer, 2016).

Nonsocial reinforcement was developed based on arousal theory (Wood et al., 1997). Arousal theory states that individuals will continually seek out stimulation due to neurological drives for the sensation (Ellis, 1987). Individuals will vary in the amount of arousal that he or she feels is ideal. Some individuals find sufficient levels of arousal in their everyday lives and do not seek additional stimulation. Others feel the need to seek out arousal beyond the mundane in order to achieve optimal levels of arousal. Those who 
require higher levels of arousal tend to be more prone to deviant behavior. Behaving deviantly is a means of increasing arousal levels for some individuals that seek out higher levels of sensation stimulation (Ellis, 1987). The connection between sensation seeking and deviant behavior is strong and yet is overlooked in social learning theory. Its inclusion in nonsocial reinforcement theory can allow for better predictions about deviant behavior, including marijuana use.

\section{Direct Effects of Theory Constructs}

Several lines of research have examined the individual influences of self-esteem and sensation seeking behavior on delinquency. Empirical evidence for the connection between self-esteem and drug use has been inconsistent. While several studies have found support for the connection between low self-esteem and high rates of drug use (Dielman, Campanelli, Shope, \& Butchart, 1987; Trzesniewski et al., 2006), several other studies have found no such connection (Moore \& Laflin, 1996). Studies that have found a connection between low self-esteem and drug use find that only a very small portion of the variance can be explained by self-esteem levels (Moore \& Laflin, 1996; Schroeder, Laflin, \& Weis, 1993). Perhaps the lack of ability for self-esteem alone to predict deviant behavior is an indicator that self-esteem is only one portion of the equation.

Wood and colleagues (1997) stated that the positive emotional response associated with deviant behavior would be a psychological reward that reinforced the behavior. In a series of six studies, Ruedy et al. (2013) found that contrary to many predictions, rather than feeling negative emotions such as remorse after amoral behavior, individuals tended to report feelings of positive emotions more frequently. Ruedy and 
colleagues (2013) termed these positive emotions a cheater's high. The cheaters high was reported by individuals who predicted they or someone like them would feel guilty after cheating on a problem-solving task. This effect persisted even in randomized experiments to remove self-selection bias from the group of individuals who cheated, when cheating did not result in a financial gain, and when cheating on the task was spelled out as immoral and wrong to reduce the individual's ability to neutralize or rationalize cheating behavior. The psychological reinforcement suggested in nonsocial reinforcement theory is supported by the positive feelings reported after amoral behavior.

Literature on the connection between sensation seeking and deviant behavior has been consistent. Neurological changes in the developing brain of adolescents has been associated with changing levels of sensation seeking throughout adolescence. The changes in levels of sensation seeking have been linked to changes in levels of deviance (Harden, Quinn, \& Tucker-Drob, 2012; Harden \& Tucker-Drob, 2011; Mann et al., 2016). Adolescents that were particularly high in sensation seeking were found to also select friends with similarly high sensation seeking and were more susceptible to peer influences compared to adolescents who were lower in sensation seeking (Mann et al., 2016). Wood et al. (1993) found that the risk-taking dimension of self-control theory was the most influential factor across various types of delinquency and the individual propensities for risk-taking may be influential in the decision-making process between seeking sensation through deviant means verses socially approved stimulation such as through organized sports. Cultural and social limitations may prevent some individuals from finding socially acceptable sources of stimulation for sensation seeking, which could lead those individuals to delinquency (Wood et al., 1993). This strong connection 
between sensation seeking and deviance adds support to the role of physiological rewards such as the thrill associated with crime as a reinforcement of the behavior.

\section{Empirical Evidence for Nonsocial Reinforcement Theory}

Evidence for nonsocial reinforcement was found by Wood et al. (1997) in an examination of incarcerated frequent offenders who highly reported the thrill of the crime. Compared to college students who were not personally familiar with the commission of the types of crimes being asked about, convicted criminals were much more likely to report positive feelings associated with the act of committing the crime. College students who were more familiar with the crime also reported more favorable feelings associated with the perpetration of the crime. While those who have presumably not committed the crime expect negative emotions to accompany crime commission, those who have presumably committed the crime, be they habitual convicted offenders, or college students, were found to associate more positive emotions with the crimes. The positive feelings associated with the crime increase the likelihood of continuation of the behavior and an increase of similar behavior, causing the reinforcing link proposed by Wood and colleagues (1997).

A survey of high school students found that substance use was related to their propensity for thrill-seeking and the physiological sensations associated with use of the substance (Wood et al., 1995). This idea of the inherent rewards reinforcing deviant behavior runs counter to many criminological theories that focus on constraints to behavior, and the individual differences in effects of substance use are not incorporated into traditional learning theory (Wood et al., 1995). 
The influence of nonsocial reinforcement was found to predict serious delinquency in incarcerated juveniles even beyond the influences of social reinforcement (Stevens et al., 2011). This study, however, suggested that nonsocial reinforcement was a larger factor in initiation of delinquent behavior than the continuation of the behavior. Social reinforcement was found to play a larger role in delinquent behavior and heavy drug use just prior to incarceration (Stevens et al., 2011). Measures of nonsocial reinforcement in this study were limited to the assessment of physiological rewards from sensation seeking. Self-esteem was not tested, nor did they utilize longitudinal data. Conclusions about the role of reinforcement from social and nonsocial sources were determined by examining the influences of risk-taking over a juvenile's lifetime and over the 12 months prior to incarceration. The relationship between risk-taking and recent deviance was not significant, however there was a significant relationship between the individual's favorable definitions of deviance and actual deviance levels in the 12 months prior to incarceration. An individual having favorable definitions of deviance is a part of social learning theory as proposed by Akers (1985), yet the methodology utilized in this study is insufficient for testing the reciprocal influence of nonsocial reinforcement on behavior. The current dissertation seeks to provide evidence of the reciprocal loop of nonsocial reinforcement on behavior.

Higgins et al. (2011) utilized longitudinal data to examine the relationships in group trends of offending and nonsocial reinforcement. The findings support the influence of nonsocial reinforcement on behavior as the grouped measures were associated with deviance over time. These grouped associations provide an indirect test of nonsocial reinforcement. Nonsocial reinforcement in this study was measured using 
only an assessment of risk-taking. Additionally, Higgins and colleagues (2011) did not account for the structural and demographic factors contributing to criminal behavior as proposed by Wood and colleagues (1997). A direct test of the reinforcing nature of nonsocial reinforcement theory is necessary to establish the reciprocal nature of nonsocial reinforcement.

Literature about the stability of nonsocial reinforcement over time has not been consistent. Higgins and colleagues (2011) found nonsocial reinforcement to be stable over time as examined in group-based longitudinal trajectories. However, Schaefer (2016) found that nonsocial reinforcement changed over time, but was able to predict juvenile violent offending and drug use. In original conceptualizations of the theory, Wood and colleagues (1997) do not speculate on the lifetime trajectory of nonsocial reinforcement theory. As previous studies have measured nonsocial reinforcement as simply a propensity for risk-taking, which has been shown in other studies to change across the life course (Harden, Quinn, \& Tucker-Drob, 2012; Harden \& Tucker-Drob, 2011), it would not be surprising to see changes in this measure over time. Changes in which behaviors are percieved as rewarding and hence reinforced and displayed more often could change over time with the individual's preferences. The cycle of reinforcement based on these rewarding preferences continues. These conflicting studies show that more research is needed on nonsocial reinforcement to fully explore the construct and its relationship to offending and drug use.

Empirical evidence for the predictive ability of nonsocial reinforcement over other criminological theories has just begun to be explored, yet these early studies are highly favorable for nonsocial reinforcement theory. In a study of juvenile male 
offenders, Jarjoura and May (2000) found that while controlling for other theoretical factors of differential association and strain, nonsocial reinforcement was still associated with robbery and firing a gun at another individual. An examination of the interaction between nonsocial reinforcement and differential association found that with reduced social rewards, reinforcement of behavior comes mostly from internal rewards inherent in nonsocial reinforcement. With increased amounts of social reinforcement, internal rewards from nonsocial reinforcement remained significant (Jarjoura \& May, 2000).

May (2003) tested nonsocial reinforcement against differential association and social control theory to determine which best predicted violent delinquency in adolescents. Findings showed that nonsocial reinforcement was the strongest predictor of behavior. This study is a key finding for nonsocial reinforcement theory as it shows the theory can predict violent behavior and do so better than several traditional theories. Another study surveyed incarcerated youth and found that nonsocial reinforcement theory was the best predictor of drug and alcohol use among the youth, outperforming social learning theory, social control theory, and strain theory. The predictive ability of nonsocial reinforcement remained strong regardless of the type of substance being examining, supporting the idea that the theory is applicable to general behavior (Cooper et al., 2009).

Higgins et al. (2009) found support for nonsocial reinforcement theory for the recreational use of tranquilizers and amphetamines, yet failed to find support in the examination of sedative use. In the study, nonsocial reinforcement was the best predictor of amphetamine use in the past 30 days among young adults in the United States, and did have a significant effect on tranquilizer use. However, support was not found for 
nonsocial reinforcement theory in the use of sedatives. It was speculated that sedatives would not satisfy the sensation seeking drive of nonsocial reinforcement, however the act of simply violating socially acceptable behavior by drug use appears to be sufficient to stimulate sensation seekers in other studies of drug using and nonsocial reinforcement theory (Cooper et al., 2009; Romer \& Hennessy, 2007). This study used a two-item assessment of risk-taking as a measure of nonsocial reinforcement, which could explain the lack of ability for nonsocial reinforcement to predict sedative use. A more complete test of the model is expected to produce more favorable results in the current dissertation.

While the evidence for the importance of nonsocial reinforcement is growing, there are still some gaps and disagreement in the literature. In order to further examine nonsocial reinforcement theory, the presumed reinforcement loop of behavior will be tested. Furthering the empirical support of the theory will lead to a better understanding of behavior and provide new avenues for interventions.

\section{Summary of Literature}

Marijuana is the most frequently used drug by Americans in every age group over 12 years old. Use of marijuana has continued to grow over the years as well as marijuana abuse disorders (Center for Behavioral Health Statistics and Quality, 2015). This growing problem requires a better understanding of the motivating factors influences the decision to use marijuana. In order to avoid the negative consequences associated with marijuana use, several different theoretical models have been utilized in the literature. Learning theories have shown great promise in the ability to predict and explain marijuana use (Akers \& Cochran, 1985; Johnson et al., 1987; Meneses \& Akers, 2011). 
One recent development in social learning is the examination of the influence of nonsocial reinforcement on the learning of behavior. Wood and colleagues' (1997) nonsocial reinforcement theory states that behavior is learned not just through reinforcement from social and tangible benefits from the behavior, but also from the nonsocial reinforcement of the physiological and psychological rewards of the behavior. Nonsocial reinforcement theory has yet to be directly tested for the reciprocal relationship of the psychological and physiological rewards reinforcing behavior and increasing the frequency of that behavior.

\section{Current Study}

The aim of the current dissertation is to evaluate the reinforcement loop proposed by nonsocial reinforcement theory. Nonsocial reinforcement theory states that behavior is reinforced by physiological and psychological rewards gained from behavior (Wood et al., 1997). This reinforcement, along with social reinforcement perpetuates habitual criminal behavior. The current dissertation isolates the nonsocial aspects of behavioral reinforcement by only examining the influences of psychological and physiological reinforcement on marijuana use. Nonsocial reinforcement theory encompasses more of the various factors influencing behavior than social learning theory, however, the theory's main premise of reinforcement of behavior has not yet been tested. The major contribution of this dissertation will be to examine the reciprocal influence of behavior and nonsocial reinforcement. This dissertation tests the longitudinal relationship of nonsocial reinforcement proposed by Wood et al. (1997). Wood and colleagues (1997) formulation of nonsocial reinforcement theory suggests that if the individual finds a 
behavior rewarding physiologically or psychologically, the behavior will be reinforced and will increase in frequency. Figure one depicts the hypothesized reciprocal effects model. As suggested by Wood and colleagues (1997) structural and situational characteristics such as race, sex, age, and socioeconomic status are expected to have a direct influence on an individual's propensity for risk-taking, the physiological stimulation found to be rewarding, self-esteem, the psychological rewards of increased positive feelings about oneself, and marijuana use. Individuals with low self-esteem and a high preference for risk-taking are expected to find the use of marijuana to be rewarding, both psychologically and physiologically. The use of marijuana is expected to increase due to the psychological and physiological rewards of the behavior. This creates a reciprocal effect over time with behavior influencing risk-taking and self-esteem which then influences the behaviors displayed.

In order to empirically verify this reciprocal effect suggested by Wood and colleagues (1997), data from two time points measuring an individual's self-esteem, risk- 
Figure 1 Reciprocal Effects Model

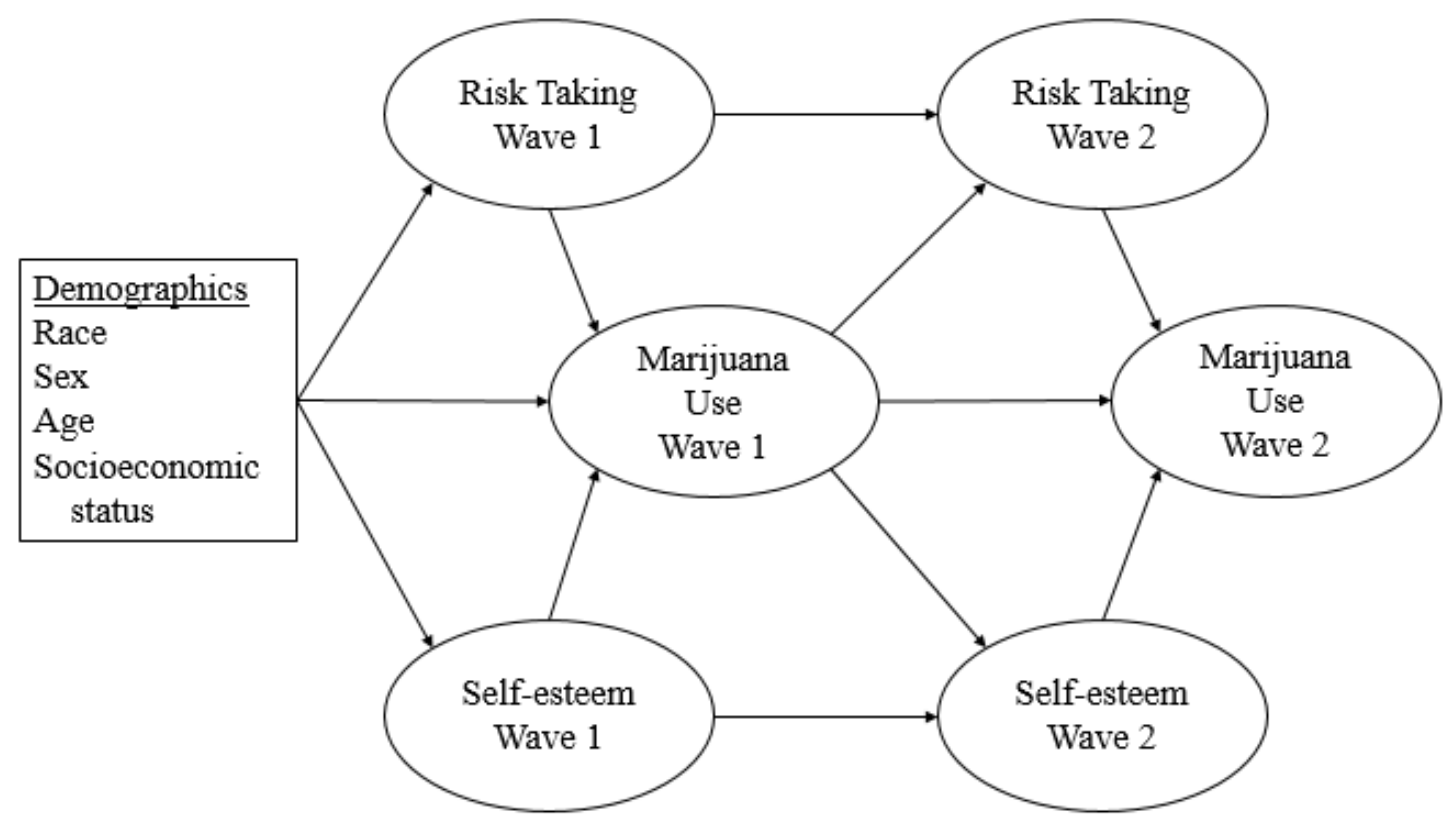

taking, and marijuana usage will be analyzed. The model suggests fourteen separate hypotheses for testing the reciprocal effects of the theory.

Wood and colleagues (1997) nonsocial Reinforcement theory predicts that demographic factors such as race, sex, age, and socioeconomic status are expected to directly influence self-esteem, risk-taking drives, and marijuana use. This provides the first three hypotheses of the current dissertation study. $\mathrm{H}_{1}$ - Demographic factors will directly relate to risk taking behavior $\mathrm{H}_{2}$ - Demographic factors will directly relate to self-esteem $\mathrm{H}_{3}$ - Demographic factors will directly relate to marijuana use

The self-esteem and risk-taking levels of individuals are then theorized to have direct effects on marijuana use. The direct relationship between both self-esteem and risk-taking on marijuana use also provides an indirect relationship between demographic factors and marijuana use as well as an indirect relationship between self-esteem and risk 
taking, and vice versa. This provides the basis for the next six hypotheses of the current dissertation.

$\mathrm{H}_{4}$ - Risk taking will directly relate to marijuana use

$\mathrm{H}_{5}$ - Demographic factors will indirectly relate to marijuana use through risk taking behavior

$\mathrm{H}_{6-}$ Demographic factors will indirectly relate to marijuana use through self-esteem $\mathrm{H}_{7}$ - Self-esteem will directly relate to marijuana use H8- Self-esteem will indirectly relate to risk-taking through marijuana use H9- Risk taking will indirectly relate to self-esteem through marijuana use Testing the longitudinal reciprocal effects of the reinforcement of psychological and physiological rewards on behavior allows for additional hypotheses. The reciprocal effect predicted by Wood and colleagues (1997) suggests that marijuana use at wave 1 will have a direct effect on self-esteem and risk-taking at wave 2. The wave 2 measures of self-esteem and risk taking are also expected to predict marijuana use at time 2. This leads to the final five hypotheses of the dissertation.

$\mathrm{H}_{10-}$ marijuana use at wave one will directly relate to self-esteem at wave two $\mathrm{H}_{11}$ - marijuana use at wave one will directly relate to risk-taking at wave two $\mathrm{H}_{12-}$ marijuana use at wave one will directly relate to marijuana use at wave two $\mathrm{H}_{13}$ - risk taking at wave 2 will directly relate to marijuana use at wave two $\mathrm{H}_{14-}$ Self-esteem at wave 2 will directly relate to marijuana use at wave two 


\section{CHAPTER III}

\section{METHODS}

The main focus of this chapter is to detail the methodology employed to test the reinforcement of behavior over time with longitudinal data. First, an overview of the goals of the dissertation are given. Second, the design of the study including the setting, sample and materials used are described. Next, the specific measures used to assess the concepts are detailed supporting their use to achieve the goals of the dissertation. Finally, the analysis plan is given which describes the means in which the data collected will be analyzed in order to test the hypotheses.

\section{Overview}

This dissertation aims at exploring the reinforcement loop of nonsocial reinforcement theory as proposed by Wood et al. (1997). Wood and colleagues (1997) state that offending is rewarded by the individual's propensity for risk taking and selfesteem along with social and material rewards. Traditional learning theories have placed more emphasis on the social rewards than the psychological and emotional rewards. This dissertation will isolate the under-studied impact of psychological and physiological rewards of behavior on the frequency of that behavior. The ability for nonsocial reinforcement to explain and predict behavior may lead to novel and more effective interventions for the prevention and cessation of deviant behavior. This dissertation will test the theory using the methods described below. 


\section{Design}

Data for this dissertation were derived from the Bureau of Labor Statistics National Longitudinal Study of Youth 1979 Young Adult cohort (NLSY79-YA). This cohort follows the children of the women surveyed in the original National Longitudinal Study of Youth 1979 (NLSY79). The original cohort for the NLSY79 study was a nationally representative sample of adolescents and young adults between the ages of 14 and 21 in 1979. The children of the women surveyed in the NLSY79 were approached for inclusion in the NLSY79-YA cohort. Over 95\% of the children possible for inclusion in the study consented to participate in the NLSY79-YA. Participants are interviewed every two years. Administration of the survey was conducted by thoroughly trained staff via telephone interviews (Bureau of Labor Statistics, n.d.). The full sample size for this cohort is 11,512. The current analysis used data collected during the 1996 and 1998 years. The years selected for the current dissertation are the result of changes to the data collected over time as the year 2000 began a pared down approach that did not collect all the perinate data for the analysis at each two-year time point. The age of participants in the study are a result of a high proportion of individuals in the sample in adolescence or young adulthood, which is a common time frame for marijuana use (Center for Behavioral Health Statistics and Quality, 2015). The sample has a large age range, and in order to focus in on the most common stages of marijuana use, the sample for the current analysis was limited to individuals between the age of 13 and 21 during the 1996 data collection. A two-year time frame between measures in the current study is sufficient to examine changes over time, yet close enough in time to presume an influence from previous measures. The use of longitudinal data will allow for the examination of 
changes over time expected with the reciprocal reinforcing effects proposed by nonsocial reinforcement theory (Wood et al., 1997).

\section{Missing Data}

Large longitudinal datasets are likely to have missing data. Appropriate ways of handling missing data are based on the expected correlations between the missing data and other variables (Enders \& Bandalos, 2001). Variables that are suspected to be missing completely at random means that strategies can be utilized knowing that the missing variables are not connected to other missing variables. However, this is a large assumption to make, especially with longitudinal data. It is possible that responses given during one wave of data collection influence missing data at another time point. For example, an individual who may not want to admit to the perceived authority figure administering the survey about recent deviant behavior may refuse to answer several questions or to be interviewed at all after knowing what questions to expect after the previous interview. A lesser assumption to make is that the missing data is missing at random (not completely at random). This reduced assumption allows for missing data that could be correlated to other data. A means of handling missing data that is robust enough to handle data that is missing is random is preferred.

When using structural equation modeling, full information maximum likelihood (FIML) strategies for handling missing data found to produce results that were unbiased in cases of variables missing at random (Enders, \& Bandalos, 2001). FIML is a means of handling missing data within the model analysis using an algorithm that finds the most likely estimates of model parameters based on the available data. This approach makes it 
possible to utilize all of the available data, even if portions are missing. Other common approaches such as listwise deletion which removes all values from a case missing data, and pairwise deletion, which remove data correlated to missing values from a case, can introduce bias into the analysis when there is an association between the missing variables (Enders, \& Bandalos, 2001).

\section{Measures}

Marijuana Use. The dependent variable of marijuana use was assessed with three questions inquiring about frequency and recency of marijuana use similar to those used in several previous studies (Krohn, Skinner, Massey, \& Akers, 1985; Lee, Akers, \& Borg, 2004). The first question asked "In your lifetime, on how many occasions have you used marijuana?" Higher scores indicate more marijuana use over the respondent's lifetime. Responses are coded on a seven-point scale where $0=$ never used marijuana, $1=$ one or two times, $3=$ three to five times, $4=$ six to ten times, $5=$ eleven to forty-nine times, $6=$ fifty to ninety-nine times, and $7=100$ times or more. The second assessment of marijuana use asked respondent "During the last 30 days, how often, if ever, have you used marijuana?" Higher scores on the six-point scale indicate more drug use. Scores consisted of 0 representing no marijuana use, one indicting less than once a week, two indicating one or two times per week, three indicating three or four times per week, four indicating five or six times per week, and a score of five indicting marijuana use every day. The third question assessing marijuana use in respondents asked "When was the most recent time you used marijuana?" Responses are given on a seven-point scale and recoded for the current study to have higher scores indicate more recent marijuana use. A 
score of zero indicates the respondent never used marijuana; $1=$ three or more years ago, $2=$ one to three years ago, $3=$ six months to a year ago, $4=$ four to six months ago, $5=$ one to three months ago, and $6=$ within the past month. Using self-report as a means of collecting information about a socially deviant behavior as marijuana use has been found to be a sufficiently valid and reliable means of assessing use (Aguinis, Pierce, \& Quigley, 1995).

Psychological Rewards. Nonsocial reinforcement as conceived by Wood and colleagues (1997) is comprised of both physiological and psychological reinforcement. Wood and colleagues (1997) conceptualize psychological rewards as things that increase an individual's self-worth. According to the theory, behavior can impact one's self-worth or self-esteem with feelings of accomplishment or failure, reinforcing or punishing the behavior. As self-esteem is a measure of overall self-worth, psychological rewards in this dissertation are examined using the Rosenberg (1965) self-esteem scale. The scale has been widely used in the self-esteem literature (Donnellan, Ackerman, \& Brecheen, 2016). The scale consists of ten items assessing the individual's overall feelings of selfworth on a four-point scale with $1=$ strongly disagree and $4=$ strongly agree. Questions on the scale are both positively worded such as "I feel that I have a number of good qualities" and "I take a positive attitude toward myself" as well as several negatively worded items such as "I feel I do not have much to be proud of" and "I wish I could have more respect for myself." Items from the scale are summed to create a measure of an individual's self-esteem. Higher scores indicate higher self-esteem.

The literature shows some disagreement about the factor structure of the scale, whether it is a unidimensional scale where all ten items are used to measure self-esteem 
on a scale from low to high self-esteem (Gray-Little, Williams, \& Hancock, 1997;

Shevlin, Bunting, \& Lewis, 1995) or a bipolar scale with items either measuring negative self-esteem or positive self-esteem (Boduszek, Hyland, Dhingra, \& Mallett, 2013).

Shevlin and colleagues (1995) found in a confirmatory factor analysis that a

unidimensional model fit well with data from college psychology undergraduate students. Gray-Little and colleagues (1997) also found a single dimension of self-esteem using item response theory in a sample of college undergraduates. Boduszek and colleagues (2013) found support for a two-dimensional confirmatory factor analysis model using a sample of ex-prisoners. McKay, Boduszek and Harvey (2014) found support for the idea that any evidence of multidimensionality in the scale is likely due to overlap in item content rather than actual multidimensionality. Tests of competing confirmatory factor analyses found that a bifactor model that assumed a unidimensional scale and accounted for item overlap was the best fit to data obtained from high school students. Additionally, another study found that models accounting for a correlation between the positive and negative self-esteem items best fit a sample of college students, indicating that a strict unidimensional model was not appropriate (Donnellan et al., 2016). Despite finding support for various models of the Rosenberg self-esteem scale, Donnellan and colleagues (2016) found little differences in measures of assocition between the various factor models tested. The current disserataion will test a unidimensional model of selfesteem that allows for the correlation between items as suggestedby Donnellann and colleages (2016).

The fit indices found using structural modeling demonstrate validity for the measure, when using the scale to create a composite score, the Rosenberg self-esteem 
scale has been shown to be a valid measure of self-esteem (Donnellan et al., 2016; GrayLittle, Williams, \& Hancock, 1997). Construct validity of the scale has been established with college students in a comparison against behavioral traits (Bagley, Bolitho, \& Bertrand, 2007). Internal consistency of the items has been demonstrated with Cronbach alpha measurements ranging from .72 to .88 (Gray-Little et al., 1997). Additionally, a composite reliability analysis was calculated to be 0.838 , where values above 0.60 are accepted in the literature (McKay et al., 2014). The scale has shown reliability across numerous cultures and languages (Schmitt \& Allik, 2005).

Physiological Rewards. Wood and colleagues (1997) conceptualized the physiological rewards influencing behavior as pleasurable sensations derived from activities of edgework, which is risk-taking, thrill-seeking behavior. Hence the current dissertation measures physiological rewards using a measure of six risk-taking variables similar to the risk-taking items used by Higgins and colleagues (2011) in their assessment of nonsocial reinforcement theory. The six questions are assessed on a four point Likert scale where one indicates a strong disagreement with the statement and four indicating a strong agreement with the statement. Questions asked in assessing risk-taking include "I think that planning takes the fun out of things," "I enjoy taking risks," "Life with no danger in it would be too dull for me," "I often get in a jam because I do things without thinking," "I have to use a lot of self-control to keep out of trouble," and "I enjoy new and exciting experiences, even if they are a little frightening or unusual." The measurement of physiological rewards using a risk taking scale is in line with Wood and colleagues (1997) conceptualization of physiological rewards based on edgework activities. Risk taking scales have been used in previous evaluations of nonsocial 
reinforcement (May, 2003). The BSSS has been used to examine the connection between risk taking in adolescence with various substance use (Romer \& Hennessy, 2007). Higher scores on the scale indicate a greater preference for risk-taking.

Demographics. Demographic data of age, sex, race, and socioeconomic status are also included in the analysis. Socioeconomic status was assessed based on employment of the respondent's father and highest grade of school completed by the father. Father's employment was based on whether the respondent's father was employed the entire year prior to the current survey administration, coded as 3, employed part of the year, coded 2, or not employed at all over the past year, coded 1. Higher scores indicating longer employment. Father's highest grade of school completed was assessed on a nine-point scale where one indicates did not finish high school, two indicates a high school education, three indicates some college, four indicates an associate's degree, five indicates a bachelor's degree, six indicates a master's degree, seven indicates a doctorate, eight indicates a law doctorate, and nine indicates a medical doctorate. Socioeconomic status was created by summing the scores of these two items.

\section{Analysis Plan}

Analysis of data for the current dissertation consists of five steps and will be carried out using Mplus (6.12). In the first step, descriptive statistics for the pertinent variables is examined. Descriptive statistics include the mean, standard deviation, minimum and maximum values, skewness and kurtosis of the data (Moore \& McCabe, 2003). The mean is the average of the scores of the variable and indicates the center of the spread of the data (Moore \& McCabe, 2003). Standard deviation refers to the square 
room of the variability of the data, giving a standardized measure of how much the data deviates from the mean (Moore \& McCabe, 2003). Minimum and maximum values in the dataset indicate the highest value measured, and the lowest value measured for that variable, giving an indication of the full range or spread of the data (Moore \& McCabe, 2003). Skewness is a measure of the shape of the distribution of the data indicating if a large amount of data falls to one side or the other of the middle of the data (Moore \& McCabe, 2003). Similarly, kurtosis is an indicator of a large amount of scores falling at the peak or middle of the data (Moore \& McCabe, 2003). Skewness and kurtosis are key measures to determine if the data is normally distributed in an approximate bell curve. This information helps determine which statistical analyses are appropriate for the given data (Moore \& McCabe, 2003).

The second step of the analysis is an examination of bivariate correlations between the key variables of the dissertation. Polyserial correlations are used to examine the extent to which paired scores from two different variables occupy the same or opposite positions within the distribution of their own variable. Polyserial correlations are utilized when data includes both a continuous and an ordinal variable. The use of typical Pearson product moment correlations with such ordinal variables can introduce a large amount of bias to the study (Olsson, Drasgow, \& Dorans, 1982). Polyserial correlations do not introduce this bias (Olsson et al., 1982). As with other correlations, Polyserial correlations give an indication of the magnitude and direction of the relationship between the two variables. Scores closer to \pm 1 indicate more congruence between the two variables. Negative scores indicate that while one variable increases, the 
other variable decreases in scores, and positive coefficients indicate that as one increases, the other also increases (Moore \& McCabe, 2003).

The third step of the analysis is a confirmatory factor analysis. Confirmatory factor analysis is used to examine the factor structure of a theoretical model and determine how well the observed variables measures a latent variable construct and provides validity for the measurements of latent variables (Kim \& Mueller, 1978). Latent variables representing constructs that cannot be measured directly are operationalized and measured using multiple survey items. Specifically, this model will test the latent variables of risk taking, self-esteem, and marijuana use at both the first measurement and second chronological measurement. Figure 2 shows the model being tested in this step. The latent variable of risk taking is measured using the six responses from the risk taking questions. The latent construct of self-esteem at both time points is measured using the ten responses from the Rosenberg self-esteem scale. The latent variable of marijuana use is measured using the three questions of marijuana use.

In the use of structural equation modeling it is important to measure latent variables with a minimum number of observed variables. Latent variables are complex traits that cannot be measured directly. The more estimates available to approximate the latent variable, the better the measurement of the variable. Degrees of freedom, which is determined by the number of observed variables and the number of parameters trying to be estimated in the model, must be positive for model identification (Raykov \& Marcoulies, 2006). The general rule of thumb for assuring model identification without 


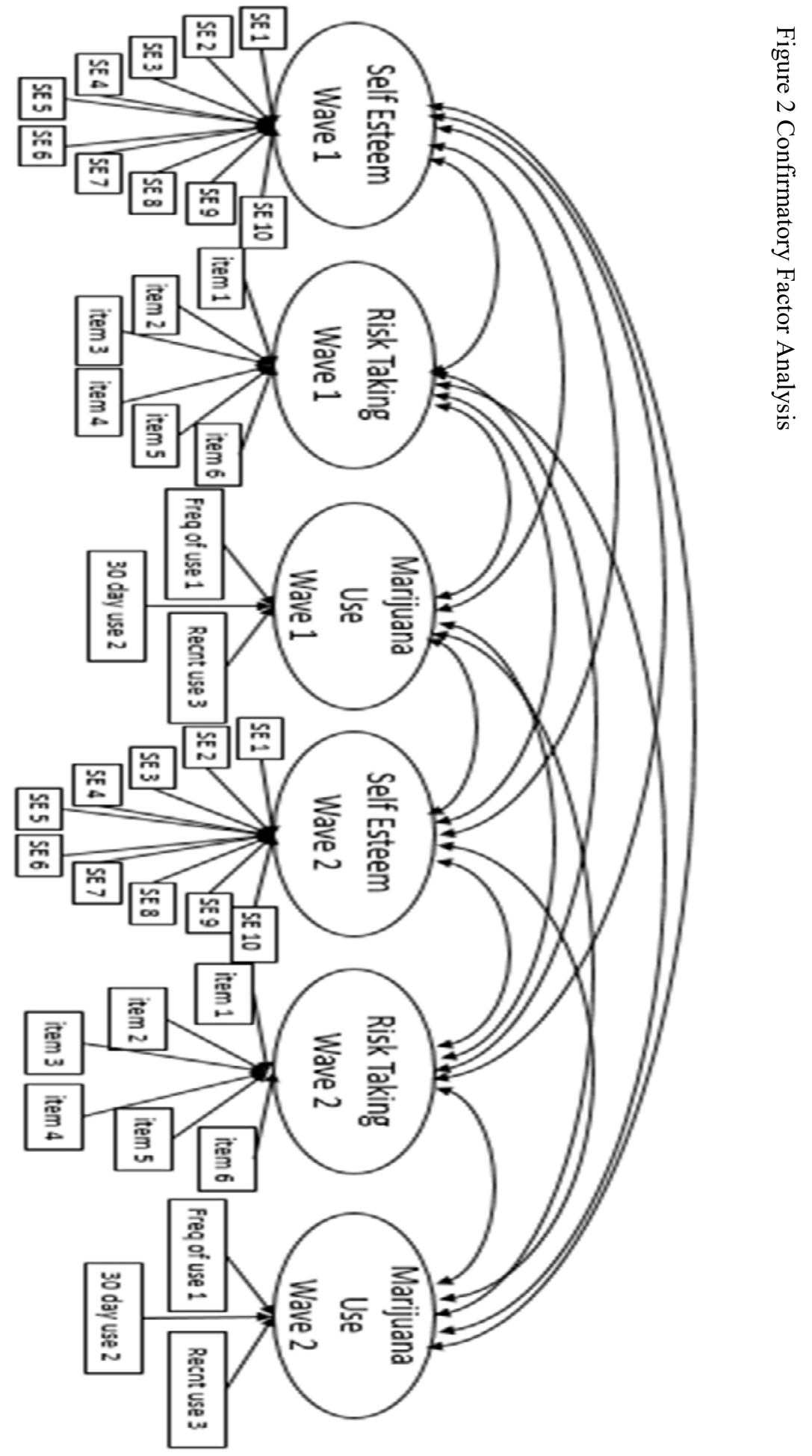


using a calculation is to assure that each latent variable is measured by at least three observed variables (Rigdon, 1995). The current dissertation specifies at least three observed variables for every latent variable, following this rule of thumb.

The measurement of latent variables in structural equation modeling is estimated by the maximum likelihood approach, which assumes that the data are normally distributed (Yuan, Bentler, \& Zhang, 2005). However, as the current data set may not be entirely normally distributed, a technique of estimation known as maximum likelihood robust (MLR) will be utilized. MLR is based on the approach taken by Yuan and Bentler (2000) to account for non-normal data in maximum likelihood estimations. MLR considers the kurtosis of the variable as it calculates parameter estimates. MLR adjusts fit indices to remove any bias that may be introduced by the use of maximum likelihood estimates on non-normal data (Yuan \& Bentler, 2000).

The measurement of model fit will be determined using factor loadings and indices of model fit of $\chi^{2}$, the comparative fit index (CFI), standardized root mean of the residual (SRMR), and the root mean standard error of approximation (RMSEA). Factor loadings above .50 are considered large in the literature and indicate importance in the model (Kline, 1998). Table 1 describes the fit indices and established thresholds for model fit. CFI examines the given model against a baseline model to determine which presents the best fit. Scores of 0.95 and above typically indicate better fit for the tested model (Hu \& Bentler, 1999). The SRMR examines the correlation between the sample and predicted population covariance as a means of examining model fit. The SRMR is best used in categorical models ( $\mathrm{Yu}, 2002)$. An index of 0.08 and below indicates a good model fit for the SRMR (Yu, 2002). The RMSEA takes into account model complexity 
and sample size. A RMSEA statistic of 0.08 and below is considered a good fit ( $\mathrm{Hu} \&$ Bentler, 1999).

Table1 Fit Indices

\begin{tabular}{|l|l|l|}
\hline Fit index & Description & Standard \\
\hline$\chi^{2}$, Chi Squared & $\begin{array}{l}\text { Examines overall model fit based on the } \\
\text { difference between the data and its } \\
\text { covariance matrix }\end{array}$ & Significance test \\
\hline $\begin{array}{l}\text { Comparative Fit Index } \\
(\text { CFI })\end{array}$ & $\begin{array}{l}\text { Compares sample covariances against a } \\
\text { null model }\end{array}$ & $\geq 0.95$ \\
\hline $\begin{array}{l}\text { Standardized Root } \\
\text { Mean of the Residual } \\
\text { (SRMR), }\end{array}$ & $\begin{array}{l}\text { Estimates the differences between the } \\
\text { sample and the estimated population } \\
\text { covariance }\end{array}$ & $\leq 0.08$ \\
\hline $\begin{array}{l}\text { Root Mean Standard } \\
\text { Error of Approximation } \\
\text { (RMSEA) }\end{array}$ & $\begin{array}{l}\text { Examines the parameter estimates as a } \\
\text { means of determining model fit and } \\
\text { favors models with the minimum number } \\
\text { of parameters possible }\end{array}$ & $\leq 0.08$ \\
\hline
\end{tabular}

Step four utilizes structural equation modeling to examine the relationship with self-esteem and risk-taking and marijuana use at both wave I and wave II separately. These two models are tested in this step in order to confirm independently of the reciprocal relationship, that a relationship exists between the risk-taking and self-esteem constructions and marijuana use. Figure 3 illustrates the relationships hypothesized to

Figure 2 Single time series path analysis
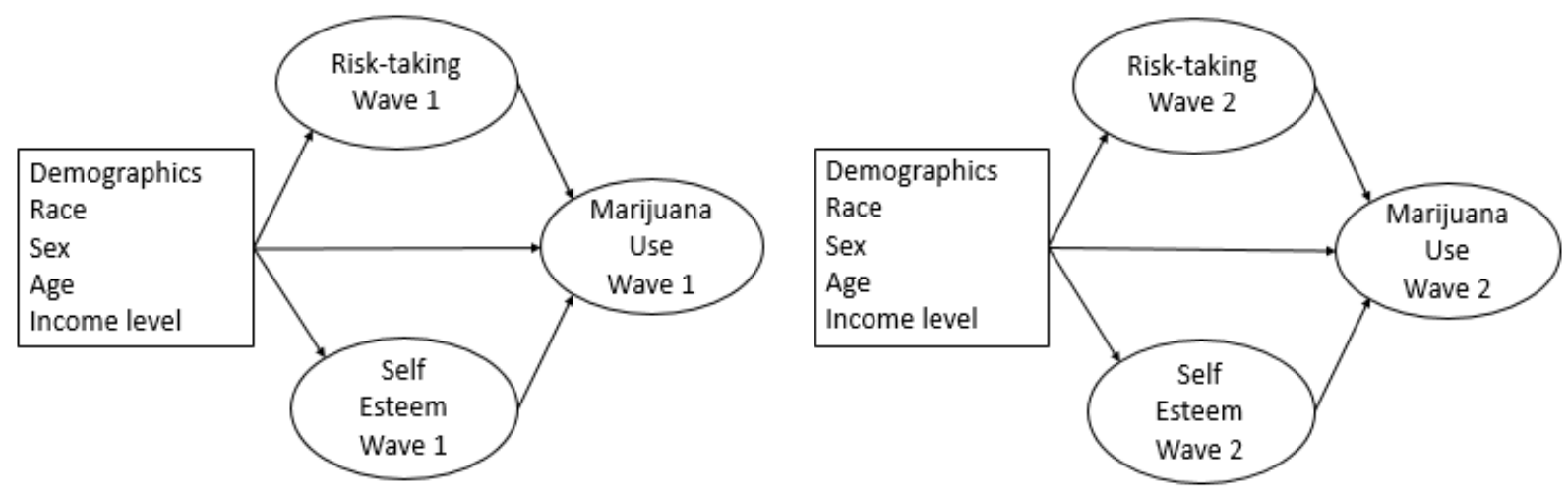
exist with a direct connection between both self-esteem and risk-taking and marijuana use. Structural equation modeling is a means of running multiple regression analyses at the same time (Kim \& Mueller, 1978). The direct relationship between self-esteem and marijuana use and risk-taking and marijuana use will be evaluated using beta weights and fit indices using $\chi^{2}$, the comparative fit index (CFI), standardized root mean of the residual (SRMR), and the root mean standard error of approximation (RMSEA). Significant beta weights are used as an indication of a direct effect between the latent variables.

Step five examines the reciprocal relationship of behavioral reinforcement suggested by Wood and colleagues (1997). The structural equation model utilized to test this relationship is given in figure 4 . The longitudinal model is tested by examining the relationships between latent variables in wave I and wave II. The full model tested in this dissertation predicts direct and indirect effects of demographic variables on risk-taking, self-esteem, and marijuana use at time one. It is expected that those who use marijuana at wave I and are high in risk-seeking and low in self-esteem will have an increase in marijuana use at wave II as the result of reinforcement from increased self-esteem and risk-taking at wave II. Standardized coefficients and fit indices as described above will be used to confirm a direct relationship between the variables. Beta weights and fit indices will be examined using $\chi^{2}$, CFI, SRMR, and RMSEA. Significant coefficients indicate a reinforcement of behavior based on physiological and psychological rewards of the behavior. 
Figure 3 Longitudinal reciprocal effects

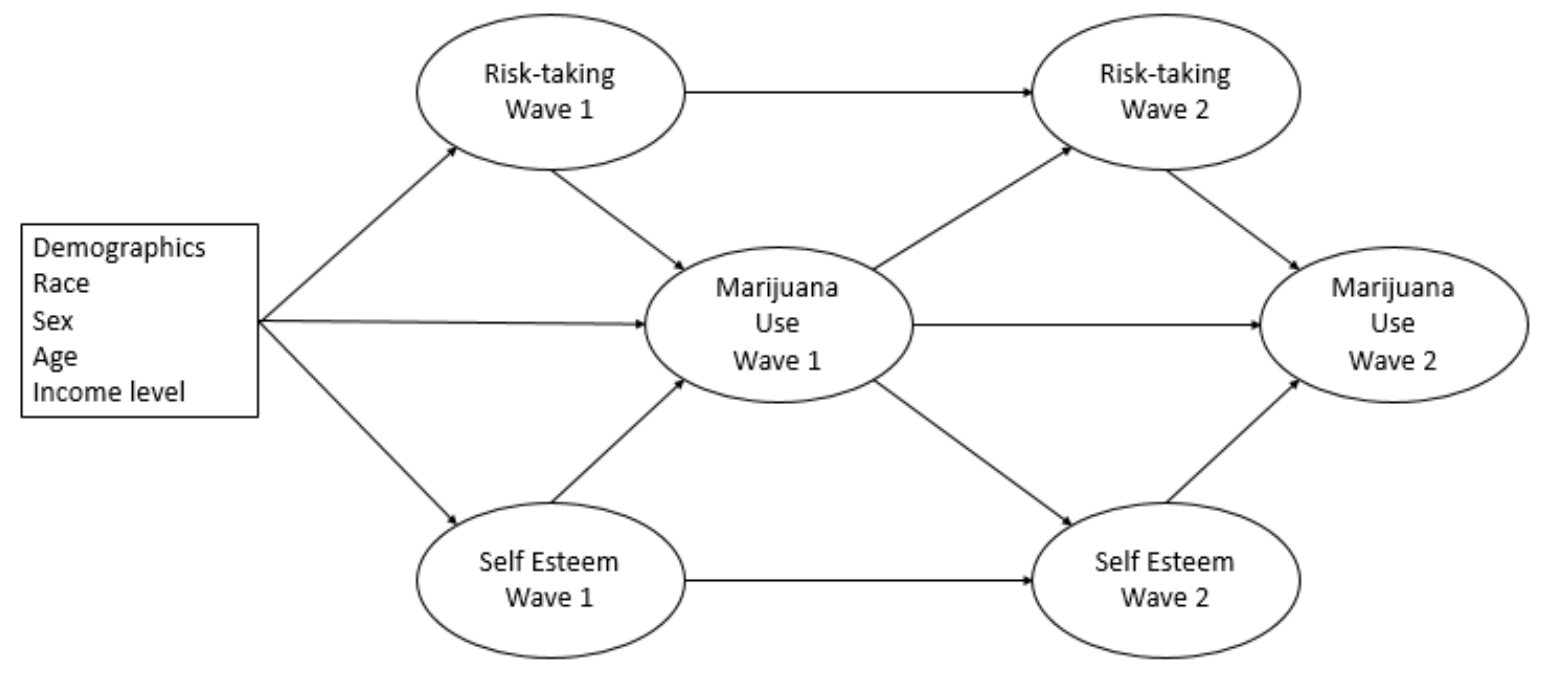




\section{CHAPTER IV}

\section{RESULTS}

\section{Overview}

This dissertation seeks to evaluate the reinforcement suggested by Wood and colleagues (1997) in nonsocial reinforcement theory. The theory suggests that behavior is reinforced by physiological and psychological rewards gained from the behavior, increasing the frequency of the behavior. In order to test this cycle of reinforcement, secondary data was used assessing the risk taking, self-esteem, and marijuana use of adolescents and young adults over a two-year period. This chapter details the results obtained from the analysis as described in the previous chapter. The first step of the analysis is an examination of descriptive statistics for the pertinent variables to understand the shape of the variable distributions. Step two is to conduct polyserial correlations between the variables to understand how the variables are associated with each other. Step three is a confirmatory factor analysis examining the fit of the observed variables used as measures of the latent variables of marijuana use, risk-taking, and selfesteem. Step four examines the direct effects of both risk-taking and self-esteem on marijuana use at both time frames examined in the analysis. Step five examines the reciprocal loop of behavioral reinforcement looking at how results from wave I influence scores during wave II. 


\section{Step 1}

The first step of the analysis in this dissertation is an examination of the descriptive statistics for key variables. Descriptive statistics examined here include the mean, standard error, skewness, kurtosis, minimum and maximum values for key variables. The examination of these descriptive statistics gives an indication of the shape of the distribution of each variable to determine if the variable is normally distributed. Table 2 lists the variables used in the analysis with descriptive statistics for each variable. Standard error, Skewness and kurtosis cannot be interpreted for dichotomous variables, therefore these measures are not given for the variables of Males, Hispanic, and African American. The analysis included a sample of 1,579 participants after removing those outside the targeted age range of 13 to 21 years old. The mean age of the sample was 16 years old. Information about the race of the participant available in the dataset was limited to categories of African American, Hispanic, and all other races. The sample consisted of 22\% Hispanic and 44\% African American. Means for marijuana use are near zero in both years examined, indicating that marijuana use was relatively low among the sample.

Standard error is a measure of the mean of the sampling distribution, or an indication of the stability or precision of the measurement of the variable. Small standard errors indicate precise measurements of the variable (George \& Mallery, 2006). The current analysis shows very small standard errors, indicating a good measurement of the variables.

Skewness, a measurement of the symmetry of the data, is one means of examining if the variables are normally distributed. The current analysis shows that many variables 
are very near zero which indicates perfect symmetry. Several variables assessing marijuana use have higher skewness, yet are still within the generally accepted range of \pm 2 for use in statistical tests that assume normal distributions (George \& Mallery, 2006). Kurtosis, examining the shape of the distribution around the peak of the data, in this analysis is also close to zero, which indicates a normal distribution. Scores in the current analysis do not exceed the threshold of \pm 2 indicating the variables are sufficiently normally distributed to continue with the subsequent analysis (George \& Mallery, 2006).

Table 2 Descriptive statistics for key variables

\begin{tabular}{|c|c|c|c|c|c|c|}
\hline$\frac{\text { Variable }}{\text { Name }}$ & Mean & $\frac{\text { Standard }}{\text { Error }}$ & Skewness & $\underline{\text { Kurtosis }}$ & $\underline{\text { Min }}$ & $\underline{\text { Max }}$ \\
\hline$\overline{\text { Males }}$ & 0.51 & - & - & - & 0 & 1 \\
\hline African Amer. & 0.43 & - & - & - & 0 & 1 \\
\hline Hispanic & 0.22 & - & - & - & 0 & 1 \\
\hline Age_96 & 16.43 & 0.29 & 0.56 & -0.58 & 13 & 21 \\
\hline SES_1996 & 1.34 & 0.03 & 0.58 & 1.24 & 2 & 12 \\
\hline MJuse96 & 0.93 & 0.03 & 1.53 & 0.95 & 0 & 6 \\
\hline MJ30dy96 & 0.34 & 0.04 & 1.58 & 1.54 & 0 & 5 \\
\hline MJrcnt96 & 1.22 & 0.03 & -0.24 & -1.49 & 0 & 6 \\
\hline RT1_96 & 2.13 & 0.04 & -0.10 & -0.73 & 1 & 4 \\
\hline RT2_96 & 1.94 & 0.04 & 0.38 & -0.10 & 1 & 4 \\
\hline RT3_96 & 2.19 & 0.04 & 0.04 & -0.98 & 1 & 4 \\
\hline RT4_96 & 2.17 & 0.04 & -0.05 & -0.65 & 1 & 4 \\
\hline RT5_96 & 2.58 & 0.04 & -0.59 & 0.37 & 1 & 4 \\
\hline RT6_96 & 2.15 & 0.04 & 0.08 & -0.80 & 1 & 4 \\
\hline SE1_96 & 3.25 & 0.12 & -0.55 & 1.25 & 1 & 4 \\
\hline SE2_96 & 3.34 & 0.15 & -0.08 & -0.13 & 1 & 4 \\
\hline SE3_96 & 3.43 & 0.16 & -0.75 & 0.81 & 1 & 4 \\
\hline SE4_96 & 3.29 & 0.15 & -0.28 & 1.10 & 1 & 4 \\
\hline SE5_96 & 3.30 & 0.14 & -0.93 & 1.15 & 1 & 4 \\
\hline SE6_96 & 3.25 & 0.13 & -0.42 & 0.64 & 1 & 4 \\
\hline SE7_96 & 3.21 & 0.16 & -0.39 & 0.86 & 1 & 4 \\
\hline SE8_96 & 2.94 & 0.15 & -0.44 & -0.32 & 1 & 4 \\
\hline SE9_96 & 2.97 & 0.15 & -0.24 & -0.49 & 1 & 4 \\
\hline SE10_96 & 3.21 & 0.15 & -0.51 & -0.06 & 1 & 4 \\
\hline Age_98 & 17.84 & 0.04 & 0.28 & -0.90 & 15 & 21 \\
\hline SES_1998 & 1.05 & 0.04 & 0.27 & 0.99 & 2 & 9 \\
\hline
\end{tabular}




\begin{tabular}{|c|c|c|c|c|c|c|}
\hline$\frac{\text { Variable }}{\text { Name }}$ & Mean & $\frac{\text { Standard }}{\underline{\text { Error }}}$ & Skewness & $\underline{\text { Kurtosis }}$ & $\underline{\text { Min }}$ & $\underline{\text { Max }}$ \\
\hline$\overline{\text { MJuse98 }}$ & 0.98 & $\overline{0.03}$ & 0.03 & -1.34 & 0 & 6 \\
\hline MJ30dy98 & 0.32 & 0.04 & 1.47 & 1.04 & 0 & 5 \\
\hline MJrcnt98 & 1.11 & 0.03 & -0.28 & -1.35 & 0 & 6 \\
\hline RT1_98 & 1.61 & 0.03 & 0.09 & -0.64 & 1 & 4 \\
\hline RT2 98 & 1.48 & 0.03 & 0.47 & 0.07 & 1 & 4 \\
\hline RT3_98 & 1.68 & 0.03 & 0.09 & -1.06 & 1 & 4 \\
\hline RT4_98 & 1.69 & 0.03 & -0.08 & -0.58 & 1 & 4 \\
\hline RT5_98 & 2.00 & 0.03 & -0.57 & 0.31 & 1 & 4 \\
\hline RT6_98 & 1.61 & 0.03 & 0.20 & -0.65 & 1 & 4 \\
\hline SE1_98 & 2.58 & 0.04 & -0.47 & 0.74 & 1 & 4 \\
\hline SE2_98 & 2.62 & 0.04 & -0.36 & 0.85 & 1 & 4 \\
\hline SE3_98 & 2.68 & 0.04 & -0.66 & 0.49 & 1 & 4 \\
\hline SE4_98 & 2.60 & 0.04 & -0.18 & 0.33 & 1 & 4 \\
\hline SE5_98 & 2.62 & 0.04 & -0.70 & 0.43 & 1 & 4 \\
\hline SE6_98 & 2.54 & 0.04 & -0.49 & 0.80 & 1 & 4 \\
\hline SE7_98 & 2.49 & 0.04 & -0.27 & 0.59 & 1 & 4 \\
\hline SE8_98 & 2.33 & 0.04 & -0.48 & -0.10 & 1 & 4 \\
\hline SE9_98 & 2.37 & 0.04 & -0.32 & -0.29 & 1 & 4 \\
\hline SE10_98 & 2.53 & 0.04 & -0.57 & 0.16 & 1 & 4 \\
\hline
\end{tabular}

\section{Step 2}

The second step of the analysis is an examination of bivariate correlations. The correlation coefficients give an indication of how each pair of variables associate with each other. Values for correlation coefficients range from 0 to \pm 1 with values closer to \pm 1 indicating a stronger association between the two variables. As expected, the analysis found that many pertinent variables are correlated. Table 3 lists correlations coefficients for all variables used in the analysis. Positive correlations are found between measurements of marijuana use and risk taking within each of the two waves of data collection. Negative, mostly nonsignificant correlations are found between marijuana use and self-esteem in 1996, however correlations turned positive and significant during the 
1998 timeframe. It is possible that age influences the relationship between self-esteem and marijuana use, which could be an interesting avenue for future study.

Correlations between risk taking measures at both time points were highly positively significant. Self-esteem measures, however, show much weaker associations across the two time points, indicating that self-esteem is a less stable trait. In 1996 there is a weak, yet sometimes significant correlation between measures of self-esteem and risk taking, indicating that those with lower self-esteem are more likely to seek out risky situations. In 1998 the relationship between self-esteem and risk taking turns positive as those with higher self-esteem are more likely to seek out risky situations. Correlations between measures of risk taking in 1996 and self-esteem in 1998 and between measures of self-esteem in 1996 and risk taking in 1998 are largely nonsignificant. Strong significant correlations within the measures of self-esteem, risk taking, and marijuana use individually within the same time frame indicate the variables are measuring the same concept as intended.

Overall the correlations indicate that the shared variance between the variables is strong enough to suggest a relationship, yet not too strong to suggest issues of multicollinearity. Multicollinearity is when variables intended to measure separate constructs are too highly correlated suggesting that the variables are actually measuring the same construct (Berry \& Feldman, 1985). Only variables with the measurement of a single latent construct exhibit high correlation coefficients, indicating that multicollinearity is not an issue with these data. This second step of the analysis examining bivariate correlations among the variables indicates that is appropriate to continue with the analysis using structural equation modeling. 
Table 3 Correlation Coefficients

\begin{tabular}{|c|c|c|c|c|c|c|c|c|c|c|c|c|c|c|}
\hline & A. & B. & $\mathrm{C}$. & D. & E. & $\mathrm{F}$. & G. & $\mathrm{H}$. & $\mathrm{I}$. & J. & $\mathrm{K}$. & $\mathrm{L}$. & M. & $\mathrm{N}$. \\
\hline A. MALES & 1.00 & & & & & & & & & & & & & \\
\hline B. AFAMER & -0.02 & 1.00 & & & & & & & & & & & & \\
\hline C. HISPANIC & 0.02 & -0.93 & 1.00 & & & & & & & & & & & \\
\hline D. AGE_96 & -0.01 & 0.12 & -0.05 & 1.00 & & & & & & & & & & \\
\hline E.SES_1996 & 0.02 & 0.22 & -0.18 & 0.07 & 1.00 & & & & & & & & & \\
\hline F. MJUSE96 & 0.08 & -0.18 & 0.21 & 0.26 & 0.05 & 1.00 & & & & & & & & \\
\hline G. MJ30DY96 & 0.07 & -0.05 & 0.16 & 0.19 & 0.08 & 0.90 & 1.00 & & & & & & & \\
\hline H. MJRCNT96 & 0.06 & -0.17 & 0.22 & 0.21 & 0.05 & 0.95 & 0.94 & 1.00 & & & & & & \\
\hline I. RT1_96 & -0.03 & -0.08 & 0.07 & -0.04 & -0.08 & 0.20 & 0.20 & 0.21 & 1.00 & & & & & \\
\hline J. RT2_96 & 0.02 & -0.11 & 0.14 & 0.04 & -0.02 & 0.21 & 0.17 & 0.20 & 0.55 & 1.00 & & & & \\
\hline K. RT3_96 & 0.01 & 0.13 & 0.02 & -0.03 & 0.00 & 0.21 & 0.19 & 0.20 & 0.53 & 0.51 & 1.00 & & & \\
\hline L. RT4_96 & 0.06 & -0.18 & 0.03 & -0.01 & 0.00 & 0.29 & 0.23 & 0.29 & 0.50 & 0.55 & 0.46 & 1.00 & & \\
\hline M. RT5_96 & -0.01 & -0.17 & 0.05 & -0.04 & 0.00 & 0.29 & 0.19 & 0.28 & 0.48 & 0.51 & 0.47 & 0.69 & 1.00 & \\
\hline N. RT6_96 & 0.12 & -0.25 & 0.08 & -0.05 & -0.06 & 0.28 & 0.23 & 0.29 & 0.50 & 0.57 & 0.48 & 0.76 & 0.66 & 1.00 \\
\hline O.SE1_96 & -0.03 & -0.01 & -0.05 & 0.15 & 0.09 & 0.05 & -0.02 & 0.05 & -0.08 & -0.03 & -0.04 & 0.07 & 0.11 & 0.02 \\
\hline P.SE2_96 & -0.04 & 0.15 & -0.10 & 0.12 & 0.11 & 0.06 & 0.04 & 0.07 & -0.14 & -0.05 & -0.02 & 0.05 & 0.12 & -0.01 \\
\hline Q. SE3_96 & -0.03 & 0.04 & -0.02 & 0.08 & 0.08 & 0.02 & -0.05 & 0.03 & -0.18 & -0.11 & -0.06 & -0.02 & 0.08 & -0.04 \\
\hline R. SE4_96 & -0.02 & 0.11 & -0.09 & 0.08 & 0.10 & 0.06 & 0.07 & 0.08 & -0.13 & -0.11 & -0.01 & 0.03 & 0.10 & -0.01 \\
\hline S. SE5_96 & -0.04 & -0.04 & -0.05 & 0.04 & 0.07 & -0.02 & -0.02 & 0.00 & -0.12 & -0.07 & -0.04 & 0.03 & 0.11 & 0.02 \\
\hline T. SE6_96 & 0.04 & 0.19 & -0.11 & 0.11 & 0.06 & 0.01 & -0.03 & 0.02 & -0.15 & -0.06 & -0.01 & 0.02 & 0.09 & -0.03 \\
\hline U.SE7_96 & -0.01 & 0.09 & -0.04 & 0.00 & 0.05 & -0.01 & -0.05 & 0.00 & -0.14 & -0.07 & -0.03 & -0.03 & 0.07 & -0.06 \\
\hline V.SE8_96 & -0.01 & -0.01 & -0.03 & 0.11 & 0.03 & 0.03 & -0.02 & 0.02 & -0.14 & -0.10 & -0.09 & 0.00 & 0.05 & -0.02 \\
\hline W. SE9_96 & 0.06 & 0.06 & -0.03 & 0.05 & 0.02 & -0.06 & -0.08 & -0.05 & -0.23 & -0.10 & -0.10 & -0.06 & -0.01 & -0.06 \\
\hline
\end{tabular}




\begin{tabular}{|c|c|c|c|c|c|c|c|c|c|c|c|c|c|c|}
\hline & A. & B. & $\mathrm{C}$. & D. & E. & $\mathrm{F}$. & G. & $\mathrm{H}$. & I. & $\mathrm{J}$. & $\mathrm{K}$. & L. & M. & N. \\
\hline X.SE10_96 & 0.05 & 0.10 & -0.06 & 0.06 & 0.03 & -0.09 & -0.12 & -0.09 & -0.20 & -0.09 & -0.08 & -0.06 & -0.01 & -0.05 \\
\hline Y.AGE_98 & .07 & .03 & 0.05 & 0.06 & -0.02 & 0.01 & 0.03 & 0.02 & 0.02 & 0.06 & 0.09 & 0.03 & 0.07 & 0.06 \\
\hline Z. SES_1998 & 0.08 & 0.07 & -0.05 & -0.17 & 0.54 & 0.02 & 0.06 & 0.04 & -0.01 & -0.05 & 0.02 & 0.03 & 0.05 & 0.01 \\
\hline AA. MJUSE98 & 0.05 & .19 & 0.11 & -0.18 & 0.01 & 0.47 & 0.41 & 0.50 & 0.15 & 0.12 & 0.12 & 0.19 & 0.17 & 0.20 \\
\hline AB. MJ30DY98 & 0.14 & -0.07 & 0.06 & -0.16 & -0.08 & 0.40 & 0.42 & 0.43 & 0.11 & 0.10 & 0.12 & 0.15 & 0.09 & 0.12 \\
\hline AC. MJRCNT98 & 0.03 & -0.19 & 0.10 & -0.21 & -0.02 & 0.42 & 0.38 & 0.47 & 0.13 & 0.12 & 0.13 & 0.19 & 0.17 & 0.19 \\
\hline AD. RT1_98 & -0.06 & -0.06 & 0.07 & -0.45 & -0.07 & -0.07 & -0.01 & -0.03 & 0.21 & 0.13 & 0.18 & 0.08 & 0.08 & 0.13 \\
\hline AE. RT2_98 & -0.03 & -0.11 & 0.11 & -0.43 & -0.04 & -0.06 & 0.01 & -0.03 & 0.11 & 0.20 & 0.16 & 0.12 & 0.07 & 0.17 \\
\hline AF. RT3_98 & 0.01 & 0.07 & 0.01 & -0.44 & 0.00 & -0.05 & 0.02 & -0.03 & 0.15 & 0.14 & 0.25 & 0.07 & 0.06 & 0.13 \\
\hline AG. RT4_98 & 0.02 & -0.19 & 0.08 & -0.45 & -0.04 & -0.06 & -0.03 & -0.03 & 0.13 & 0.15 & 0.15 & 0.22 & 0.18 & 0.21 \\
\hline AH. RT5_98 & -0.01 & -0.17 & 0.08 & -0.49 & -0.04 & -0.07 & -0.03 & -0.04 & 0.11 & 0.11 & 0.14 & 0.15 & 0.19 & 0.19 \\
\hline AI. RT6_98 & 0.05 & -0.22 & 0.09 & -0.45 & -0.07 & -0.06 & 0.00 & -0.03 & 0.12 & 0.14 & 0.13 & 0.18 & 0.16 & 0.25 \\
\hline AJ.SE1_98 & -0.04 & -0.02 & -0.01 & -0.44 & -0.05 & -0.06 & -0.06 & -0.04 & -0.01 & 0.01 & 0.06 & 0.10 & 0.13 & 0.11 \\
\hline AK. SE2_98 & -0.06 & 0.02 & 0.01 & -0.42 & -0.04 & -0.07 & -0.07 & -0.05 & 0.01 & 0.02 & 0.08 & 0.08 & 0.12 & 0.11 \\
\hline AL. SE3_98 & -0.04 & -0.01 & 0.03 & -0.45 & -0.04 & -0.11 & -0.10 & -0.07 & 0.01 & 0.00 & 0.08 & 0.07 & 0.11 & 0.10 \\
\hline AM. SE4_98 & -0.05 & 0.01 & 0.02 & -0.45 & -0.01 & -0.10 & -0.07 & -0.06 & -0.01 & -0.01 & 0.09 & 0.06 & 0.11 & 0.08 \\
\hline AN. SE5_98 & -0.07 & -0.02 & 0.01 & -0.44 & -0.05 & -0.12 & -0.11 & -0.10 & 0.02 & 0.02 & 0.10 & 0.06 & 0.11 & 0.09 \\
\hline AO. SE6_98 & -0.02 & 0.08 & -0.01 & -0.43 & -0.04 & -0.12 & -0.07 & -0.08 & -0.02 & 0.00 & 0.09 & 0.06 & 0.11 & 0.08 \\
\hline AP. SE7_98 & -0.03 & 0.02 & 0.02 & -0.47 & -0.06 & -0.12 & -0.08 & -0.09 & -0.01 & 0.00 & 0.08 & 0.04 & 0.10 & 0.08 \\
\hline AQ.SE8_98 & -0.07 & 0.02 & 0.02 & -0.41 & -0.03 & -0.10 & -0.09 & -0.08 & -0.02 & -0.03 & 0.07 & 0.05 & 0.10 & 0.09 \\
\hline AR. SE9_98 & -0.01 & 0.00 & 0.04 & -0.44 & -0.02 & -0.11 & -0.11 & -0.09 & -0.03 & 0.00 & 0.07 & 0.04 & 0.10 & 0.09 \\
\hline AS. SE10_98 & -0.02 & 0.03 & 0.02 & -0.43 & -0.05 & -0.12 & -0.11 & -0.10 & -0.03 & 0.00 & 0.06 & 0.05 & 0.11 & 0.09 \\
\hline
\end{tabular}




\begin{tabular}{|c|c|c|c|c|c|c|c|c|c|c|c|c|c|c|}
\hline & $\mathrm{O}$. & $\mathrm{P}$. & Q. & $\mathrm{R}$. & $\mathrm{S}$. & T. & U. & $\mathrm{V}$. & W. & $\mathrm{X}$. & $\mathrm{Y}$. & $\mathrm{Z}$. & AA. & $\mathrm{AB}$. \\
\hline O. SE1_96 & 1.00 & & & & & & & & & & & & & \\
\hline P. SE2_96 & 0.68 & 1.00 & & & & & & & & & & & & \\
\hline Q. SE3_96 & 0.52 & 0.65 & 1.00 & & & & & & & & & & & \\
\hline R. SE4_96 & 0.53 & 0.65 & 0.56 & 1.00 & & & & & & & & & & \\
\hline S. SE5_96 & 0.47 & 0.54 & 0.65 & 0.52 & 1.00 & & & & & & & & & \\
\hline T. SE6_96 & 0.48 & 0.64 & 0.55 & 0.56 & 0.53 & 1.00 & & & & & & & & \\
\hline V.SE8_96 & 0.35 & 0.40 & 0.46 & 0.36 & 0.46 & 0.41 & 0.41 & 1.00 & & & & & & \\
\hline W. SE9_96 & 0.37 & 0.42 & 0.52 & 0.42 & 0.53 & 0.45 & 0.48 & 0.45 & 1.00 & & & & & \\
\hline X. SE10_96 & 0.39 & 0.48 & 0.54 & 0.42 & 0.55 & 0.49 & 0.52 & 0.46 & 0.73 & 1.00 & & & & \\
\hline Y.AGE_98 & 0.01 & 0.04 & 0.06 & 0.00 & 0.01 & 0.06 & 0.09 & -0.01 & 0.03 & 0.03 & 1.00 & & & \\
\hline Z.SES_1998 & 0.08 & 0.09 & 0.14 & 0.08 & 0.10 & 0.05 & 0.10 & -0.01 & 0.00 & 0.05 & 0.33 & 1.00 & & \\
\hline AE. RT2_98 & -0.10 & -0.11 & -0.10 & -0.10 & -0.12 & -0.10 & -0.03 & -0.13 & -0.09 & -0.09 & 0.50 & 0.23 & 0.46 & 0.41 \\
\hline AF. RT3_98 & -0.13 & -0.12 & -0.08 & -0.10 & -0.11 & -0.05 & -0.02 & -0.11 & -0.08 & -0.09 & 0.48 & 0.25 & 0.47 & 0.41 \\
\hline AG. RT4_98 & -0.06 & -0.05 & -0.03 & -0.04 & -0.03 & -0.04 & 0.01 & -0.08 & -0.06 & -0.06 & 0.47 & 0.25 & 0.53 & 0.43 \\
\hline AH. RT5_98 & -0.03 & -0.02 & 0.03 & 0.01 & 0.02 & 0.01 & 0.05 & -0.02 & -0.02 & -0.02 & 0.47 & 0.27 & 0.52 & 0.39 \\
\hline AI. RT6_98 & -0.08 & -0.10 & -0.06 & -0.08 & -0.05 & -0.05 & -0.01 & -0.10 & -0.07 & -0.07 & 0.46 & 0.24 & 0.52 & 0.42 \\
\hline AJ. SE1_98 & 0.09 & 0.15 & 0.18 & 0.10 & 0.16 & 0.12 & 0.19 & 0.08 & 0.10 & 0.13 & 0.67 & 0.39 & 0.37 & 0.26 \\
\hline AK. SE2_98 & 0.08 & 0.17 & 0.18 & 0.14 & 0.17 & 0.15 & 0.21 & 0.10 & 0.11 & 0.14 & 0.70 & 0.38 & 0.36 & 0.28 \\
\hline AL. SE3_98 & 0.06 & 0.14 & 0.19 & 0.09 & 0.15 & 0.12 & 0.19 & 0.08 & 0.10 & 0.12 & 0.67 & 0.36 & 0.32 & 0.22 \\
\hline AM. SE4_98 & 0.06 & 0.12 & 0.13 & 0.15 & 0.16 & 0.13 & 0.22 & 0.07 & 0.13 & 0.13 & 0.68 & 0.36 & 0.35 & 0.24 \\
\hline
\end{tabular}




\begin{tabular}{|c|c|c|c|c|c|c|c|c|c|c|c|c|c|c|}
\hline & O. & P. & Q. & R. & S. & T. & U. & V. & W. & $\mathrm{X}$. & Y. & Z. & AA. & AB. \\
\hline AN. SE5_98 & 0.07 & 0.12 & 0.15 & 0.10 & 0.17 & 0.13 & 0.19 & 0.06 & 0.11 & 0.12 & 0.66 & 0.34 & 0.31 & 0.19 \\
\hline AO. SE6_98 & 0.06 & 0.13 & 0.17 & 0.12 & 0.16 & 0.19 & 0.23 & 0.11 & 0.15 & 0.16 & 0.67 & 0.37 & 0.31 & 0.22 \\
\hline AP.SE7_98 & 0.01 & 0.08 & 0.12 & 0.09 & 0.13 & 0.12 & 0.21 & 0.06 & 0.12 & 0.13 & 0.64 & 0.38 & 0.30 & 0.24 \\
\hline AQ. SE8_98 & 0.07 & 0.11 & 0.15 & 0.10 & 0.16 & 0.14 & 0.21 & 0.15 & 0.13 & 0.14 & 0.64 & 0.35 & 0.29 & 0.22 \\
\hline AR. SE9_98 & 0.07 & 0.14 & 0.15 & 0.12 & 0.17 & 0.14 & 0.21 & 0.14 & 0.23 & 0.24 & 0.63 & 0.35 & 0.25 & 0.14 \\
\hline AS. SE10_98 & 0.06 & 0.12 & 0.15 & 0.12 & 0.15 & 0.15 & 0.22 & 0.12 & 0.17 & 0.21 & 0.66 & 0.35 & 0.30 & 0.20 \\
\hline
\end{tabular}

\begin{tabular}{|l|l|l|l|l|l|l|l|l|l|l|l|l|l|}
\hline & AB. & AC. & AD. & AE. & AF. & AG. & AH. & AI. & AJ. & AK. & AL. & AM. & AN. \\
\hline AB. MJ30DY98 & 1.00 & & & & & & & & & & & & \\
\hline AC. MJRCNT98 & 0.93 & 1.00 & & & & & & & & & & & \\
\hline AD. RT1_98 & 0.43 & 0.51 & 1.00 & & & & & & & & & & \\
\hline AE. RT2_98 & 0.41 & 0.47 & 0.74 & 1.00 & & & & & & & & & \\
\hline AF. RT3_98 & 0.41 & 0.47 & 0.77 & 0.73 & 1.00 & & & & & & & & \\
\hline AG. RT4_98 & 0.43 & 0.52 & 0.71 & 0.74 & 0.70 & 1.00 & & & & & & & \\
\hline AH. RT5_98 & 0.39 & 0.54 & 0.70 & 0.72 & 0.72 & 0.85 & 1.00 & & & & & & \\
\hline AI. RT6_98 & 0.42 & 0.53 & 0.69 & 0.75 & 0.70 & 0.84 & 0.83 & 1.00 & & & & & \\
\hline AJ. SE1_98 & 0.26 & 0.37 & 0.54 & 0.56 & 0.56 & 0.62 & 0.67 & 0.62 & 1.00 & & & & \\
\hline AK. SE2_98 & 0.28 & 0.36 & 0.55 & 0.58 & 0.58 & 0.60 & 0.67 & 0.60 & 0.94 & 1.00 & & & \\
\hline AL. SE3_98 & 0.22 & 0.34 & 0.54 & 0.58 & 0.56 & 0.61 & 0.67 & 0.60 & 0.91 & 0.92 & 1.00 & & \\
\hline AM. SE4_98 & 0.24 & 0.34 & 0.54 & 0.57 & 0.59 & 0.62 & 0.67 & 0.60 & 0.90 & 0.93 & 0.91 & 1.00 & \\
\hline AN. SE5_98 & 0.19 & 0.32 & 0.54 & 0.56 & 0.55 & 0.60 & 0.65 & 0.59 & 0.89 & 0.90 & 0.92 & 0.89 & 1.00 \\
\hline
\end{tabular}




\begin{tabular}{|c|c|c|c|c|c|c|c|c|c|c|c|c|c|}
\hline & AB. & AC. & AD. & AE. & AF. & AG. & AH. & AI. & AJ. & AK. & AL. & AM. & AN. \\
\hline AO. SE6_98 & 0.22 & 0.30 & 0.51 & 0.56 & 0.57 & 0.59 & 0.64 & 0.57 & 0.89 & 0.91 & 0.92 & 0.91 & 0.90 \\
\hline AP. SE7_98 & 0.24 & 0.30 & 0.52 & 0.57 & 0.57 & 0.60 & 0.67 & 0.59 & 0.86 & 0.88 & 0.87 & 0.88 & 0.88 \\
\hline AQ. SE8_98 & 0.22 & 0.29 & 0.48 & 0.51 & 0.48 & 0.54 & 0.60 & 0.55 & 0.82 & 0.84 & 0.86 & 0.81 & 0.83 \\
\hline AR. SE9_98 & 0.14 & 0.25 & 0.47 & 0.52 & 0.49 & 0.55 & 0.59 & 0.53 & 0.83 & 0.84 & 0.87 & 0.85 & 0.86 \\
\hline AS. SE10_98 & 0.20 & 0.28 & 0.47 & 0.54 & 0.51 & 0.57 & 0.62 & 0.56 & 0.87 & 0.88 & 0.90 & 0.88 & 0.88 \\
\hline
\end{tabular}

\begin{tabular}{|l|l|l|l|l|l|}
\hline & AO. & AP. & AQ. & AR. & AS. \\
\hline AO. SE6_98 & 1.00 & & & & \\
\hline AP. SE7_98 & 0.89 & 1.00 & & & \\
\hline AQ. SE8_98 & 0.85 & 0.82 & 1.00 & & \\
\hline AR. SE9_98 & 0.87 & 0.86 & 0.84 & 1.00 & \\
\hline AS. SE10_98 & 0.90 & 0.87 & 0.86 & 0.93 & 1.00 \\
\hline
\end{tabular}




\section{Step 3}

The third step of the analysis is a confirmatory factor analysis. The confirmatory factor analysis is a means of confirming that the latent variables are appropriately measured with the observed variables. This analysis provides convergent and discriminate validity to the model. Convergent validity is a means of showing that theorized associations between measures are in fact connected (Hagan, 1997).

Discriminant validity is an indication that measures that should not be associated, are not associated (Hagan, 1997). In the current model, if questions relating to risk taking were found to have a stronger association with the latent variable of self-esteem, the measurement of the model would fail to meet discriminant validity standards.

The confirmatory factor analysis found the model fit the data. Table 4 gives the factor loadings and fit indices from the analysis. The $\chi^{2}$ index is significant $\left(\chi^{2}=\right.$ 2835.462, $\mathrm{p}<0.001$ ), which indicates that the model differs significantly from the data. This significance is the result of the large sample size utilized in the analysis as $\chi^{2}$ is sensitive to large samples and increases the possibility of a type I error, incorrectly rejecting the true model (Bentler \& Bonnett, 1980). The sample size in the current analysis is 1,579 , indicating that the significance of $\chi^{2}$ is likely the result of bias from a large sample size. Other measures of model fit are examined to assure the model does fit the data. The CFI is 0.993 , which is above the cutoff of 0.95 which considered a good fit (Hu \& Bentler, 1999). SRMR and RMSEA of 0.035 and 0.046 are well within the standards for good model fit (Hu \& Bentler, 1999).

The factor loadings for the model, as seen in table 4 , are all over 0.5 which is considered large (Kline, 1998). The factor loadings give an indication of the strength of 
the relationship between the observed variable and the latent variable (Kline, 1998).

Strong factor loadings in the current analysis indicate that the observed measures used are a good approximation of the latent variable. This analysis supports the measures used for the latent variables of self-esteem, risk taking, and marijuana use at waves 1 and 2.

Table 4 Confirmatory Factor Analysis Factor Loadings

\begin{tabular}{|c|c|c|}
\hline Variable relationship & $\begin{array}{l}\text { Standardized } \\
\text { coefficient } 1996\end{array}$ & $\begin{array}{l}\text { Standardized } \\
\text { coefficient } 1998 \\
\end{array}$ \\
\hline \multicolumn{3}{|l|}{ Risk taking and } \\
\hline RT1 & $0.672^{* *}$ & $0.811^{* *}$ \\
\hline RT2 & $0.702^{* *}$ & $0.841^{* *}$ \\
\hline RT3 & $0.646^{* *}$ & $0.829 * *$ \\
\hline RT4 & $0.846^{* *}$ & $0.905^{* *}$ \\
\hline RT5 & $0.769 * *$ & $0.930 * *$ \\
\hline RT6 & $0.846^{* *}$ & $0.891^{* *}$ \\
\hline \multicolumn{3}{|l|}{ Self Esteem and } \\
\hline SE1 & $0.661^{* *}$ & $0.947^{* *}$ \\
\hline SE2 & $0.803^{* *}$ & $0.965 * *$ \\
\hline SE3 & $0.780^{* *}$ & $0.958^{* *}$ \\
\hline SE4 & $0.707^{* *}$ & $0.950 * *$ \\
\hline SE5 & $0.738^{* *}$ & $0.944 * *$ \\
\hline SE6 & $0.746^{* *}$ & $0.950 * *$ \\
\hline SE7 & $0.728^{* *}$ & $0.927^{* *}$ \\
\hline SE8 & $0.568^{* *}$ & $0.884^{* *}$ \\
\hline SE9 & $0.728^{* *}$ & $0.924 * *$ \\
\hline SE10 & $0.758^{* *}$ & $0.948 * *$ \\
\hline \multicolumn{3}{|l|}{ Marijuana use and } \\
\hline MJUSE1 & $0.951^{* *}$ & $0.956 * *$ \\
\hline MJ30DAY & $0.941^{* *}$ & $0.921 * *$ \\
\hline MJCRNT & $1.001^{* *}$ & $0.993 * *$ \\
\hline
\end{tabular}

\section{Correlations}

Self-esteem 1996 and risk taking 1996

Self-esteem 1996 and marijuana use 1996

Self-esteem 1996 and self-esteem 1998

Self-esteem 1996 and risk taking 1998

Self-esteem 1996 and
$-0.032 * *$
$-0.004$
$0.127^{* *}$
$-0.059 * *$
$-0.07 * *$ 
marijuana use 1998

Risk taking 1996 and marijuana use 1996

Risk taking 1996 and self-esteem 1998

Risk taking 1996 and risk taking 1998

Risk taking 1996 and marijuana use 1998

Marijuana use 1996 and self-esteem 1998

Marijuana use 1996 and risk taking 1998

Marijuana use 1996 and marijuana use 1998

Self-esteem 1998 and risk taking 1998

Self-esteem 1998 and marijuana use 1998

Risk taking 1998 and Marijuana use 1998

Fit Indices

$* * p<.01 \quad \begin{array}{r}\chi^{2} \\ \text { CFI } \\ \text { SRMR } \\ \text { RMSEA }\end{array}$

\begin{tabular}{|c|c|} 
& $0.208^{* *}$ \\
& $0.052^{* *}$ \\
& $0.126^{* *}$ \\
& $0.131^{* *}$ \\
- & $0.087^{* *}$ \\
-0.032 \\
$0.432^{* *}$ \\
$0.541^{* *}$ \\
$0.297^{* *}$ \\
$0.45^{* *}$ \\
0.046 \\
0.993 \\
$0.0352^{* *}$ \\
\end{tabular}

\section{Step 4}

Structural equation modeling is a means of running multiple regression analyses at the same time. In step four structural equation modeling was used to evaluate the relationship between demographic factors of race, sex, age, and socioeconomic status, risk-taking, self-esteem, and marijuana use. Two separate models were utilized to examine the relationship between the variables at both wave 1 and wave 2 of data collection. Confirmation of these relationships will support the use of self-esteem and risk-taking as reinforcing marijuana use. Wood and colleagues (1997) hypothesized that 
behavior will be perpetuated based on reinforcement not just from social rewards, but also psychological and physiological rewards. This step in the analysis confirms the hypothesized cross-sectional association between the psychological and physiological rewards of self-esteem and risk taking and their relationship with marijuana use.

The current analysis found that the model fit the data well. Measurements of model fit for both models are given in table 5. As expected, $\chi^{2}$ is significant in both models $\left(\chi^{2}=1401.836, \mathrm{p}<0.01 ; \chi^{2}=1107.514, \mathrm{p}<0.01\right)$ which is likely due to the large sample size. Other measurements of model fit exceeded expected thresholds indicating good model fit for both models examined in this step. A good model fit indicates that the structure of the model accurately fits the data.

Table 5 Cross-sectional Structural Model Analysis

\begin{tabular}{|c|c|c|}
\hline$\underline{\text { Variable relationship }}$ & 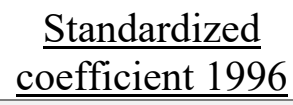 & 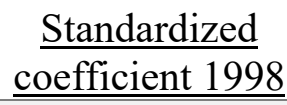 \\
\hline SES $\rightarrow$ Risk taking & -0.007 & -0.007 \\
\hline Males $\rightarrow$ Risk taking & 0.032 & 0.028 \\
\hline Hispanic $\rightarrow$ Risk taking & -0.001 & -0.027 \\
\hline African American $\rightarrow$ Risk Taking & $-0.125 * *$ & $-0.099 * *$ \\
\hline Age $\rightarrow$ Risk taking & -0.029 & $0.861 * *$ \\
\hline SES $\rightarrow$ Self-esteem & $0.063 *$ & 0.009 \\
\hline Males $\rightarrow$ Self-esteem & 0.000 & 0.013 \\
\hline Hispanic $\rightarrow$ Self-esteem & -0.025 & -0.023 \\
\hline African American $\rightarrow$ Self-esteem & 0.047 & 0.000 \\
\hline Age $\rightarrow$ Self-esteem & $0.097 * *$ & $0.925 * *$ \\
\hline $\mathrm{SES} \rightarrow$ Marijuana use & $0.067 *$ & 0.043 \\
\hline Males $\rightarrow$ Marijuana use & 0.049 & 0.047 \\
\hline Hispanic $\rightarrow$ Marijuana use & $0.115 * *$ & 0.009 \\
\hline African American $\rightarrow$ Marijuana use & -0.056 & -0.056 \\
\hline Age $\rightarrow$ Marijuana use & $0.241 * *$ & 0.258 \\
\hline Risk taking $\rightarrow$ Marijuana use & $0.382 * *$ & $0.602 * *$ \\
\hline Self-esteem $\rightarrow$ Marijuana use & -0.018 & $-0.150 *$ \\
\hline \multicolumn{3}{|l|}{ Fit indices } \\
\hline$\chi^{2}$ & $1401.836^{* *}$ & $1107.514^{* *}$ \\
\hline
\end{tabular}




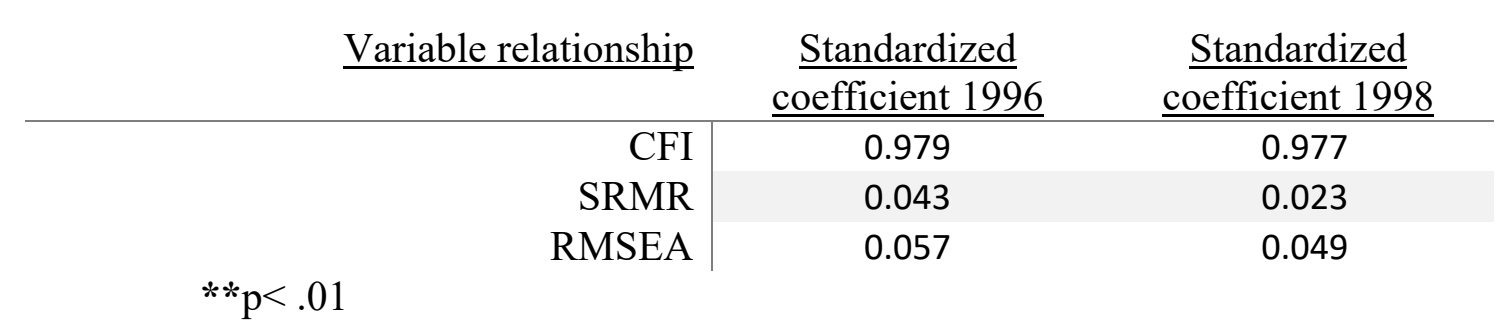

An examination of standardized coefficients between the latent variables and between the observed demographic variables and latent variables gives an indication of the strength of the relationship on a standardized scale for the comparison across different relationships. Standardized coefficients are given in table 5 for both models run in this step. Hypotheses 1-3 in the current dissertation predicted direct effects of demographics on self-esteem, risk taking and marijuana use. The analysis found that not being an African American was significantly related to an individual's propensity for risk taking. Age was only associated with risk taking during the 1998 wave. Age was positively associated with self-esteem at both time points. Socioeconomic status only played a role in self-esteem during the 1996 wave of data collection. Marijuana use was related to age, being Hispanic, and an individual's socioeconomic status during the 1996 wave of data collection, but were not significant during the 1998 wave of data collection. These weak and inconsistent connections between demographics and risk taking, self-esteem, and marijuana use could be the result of widespread marijuana use amongst the population, regardless of socioeconomic status, race and gender (Inciardi, 2002).

Hypothesis 4 predicts that there will be a direct relationship between risk-taking and marijuana use, which is supported by significant standardized coefficients in both waves of data collection. The effects of risk taking on marijuana use at both waves of data collection are highly significant. As expected, an individual's propensity for risk 
taking is significantly related to marijuana use in a cross-sectional design. This supports Wood and colleagues' (1997) formulation of nonsocial reinforcement theory.

Hypotheses 5 and 6 predict that demographic factors will have an indirect effect on marijuana use through risk taking behavior and self-esteem. Table 6 shows the indirect relationships found in the cross-sectional models. No significant indirect relationships were found in the 1996 model. Age was found to indirectly relate to marijuana use through both risk taking and self-esteem. Not being an African American was related to marijuana use through risk taking only. Again, relationships between demographic characteristics and latent variables, including marijuana use, may be nonsignificant as a result of the widespread use of marijuana across all demographic characteristics (Inciardi, 2002).

Hypothesis 7 proposes that there will be a direct relationship between self-esteem and marijuana use. Self-esteem is significantly related to marijuana use during the 1998 data collection, yet is not related to marijuana use in the 1996 wave. The inconsistent results of the relationship between self-esteem and marijuana use may be related to the inconsistent results found in the literature connecting self-esteem and drug use (Moore \& Laflin, 1996). The relationship between low self-esteem and marijuana use found in the 1998 model warrants further examination of this relationship in the longitudinal model in the next step of this analysis.

Table 6 Indirect relationships in Cross-sectional Models

\begin{tabular}{|c|c|c|}
\hline$\underline{\text { Variable relationship }}$ & $\begin{array}{c}\text { Standardized } \\
\text { coefficient } 1996 \\
\end{array}$ & $\frac{\text { Standardized }}{\text { coefficient } 1998}$ \\
\hline SES $\rightarrow$ Risk taking $\rightarrow$ Marijuana use & -0.002 & -0.004 \\
\hline Males $\rightarrow$ Risk taking $\rightarrow$ Marijuana use & 0.010 & 0.017 \\
\hline Hispanic $\rightarrow$ Risk taking $\rightarrow$ Marijuana use & 0.000 & -0.016 \\
\hline African American $\rightarrow$ Risk Taking $\rightarrow$ Marijuana use & -0.041 & $-0.060 *$ \\
\hline
\end{tabular}




\begin{tabular}{|c|c|c|}
\hline Variable relationship & 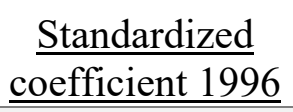 & 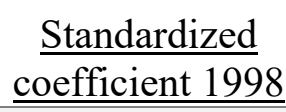 \\
\hline Age $\rightarrow$ Risk taking $\rightarrow$ Marijuana use & -0.010 & $0.518^{* *}$ \\
\hline $\mathrm{SES} \rightarrow$ Self-esteem $\rightarrow$ Marijuana use & -0.001 & -0.001 \\
\hline Males $\rightarrow$ Self-esteem $\rightarrow$ Marijuana use & 0.000 & -0.002 \\
\hline Hispanic $\rightarrow$ Self-esteem $\rightarrow$ Marijuana use & 0.000 & 0.003 \\
\hline African American $\rightarrow$ Self-esteem $\rightarrow$ Marijuana use & -0.001 & 0.000 \\
\hline $\begin{array}{l}\text { Age } \rightarrow \text { Self-esteem } \rightarrow \text { Marijuana use } \\
\mathrm{p}<.05 * * \mathrm{p}<.01\end{array}$ & -0.002 & $-0.139 * *$ \\
\hline
\end{tabular}

\section{Step 5}

Step five tests the reciprocal loop of behavioral reinforcement in nonsocial learning theory utilizing longitudinal data. The model tested in this step examines the relationship between demographic factors and wave one measurements of self-esteem, risk taking, and marijuana use, and the wave one measurements relationships to wave two measurements of self-esteem, risk taking, and marijuana use.

The model tested in step five is given above in figure 1. Upon examination of the fit indices, the model did not sufficiently fit the data. An examination of the modification indices and the significance of demographic variables in the 1998 cross-sectional model suggested that the inclusion of relationships between demographics and 1998 wave latent variables of self-esteem and risk taking could better fit the data without violating the premise of the theory. Figure 5 shows the modified model tested, which did fit the data. 
Fit indices for the modified model were examined using $\chi^{2}$, CFI, SRMR, and RMSEA as with previous models examined in the dissertation.

Figure 5 Modified Reciprocal Relationship Model

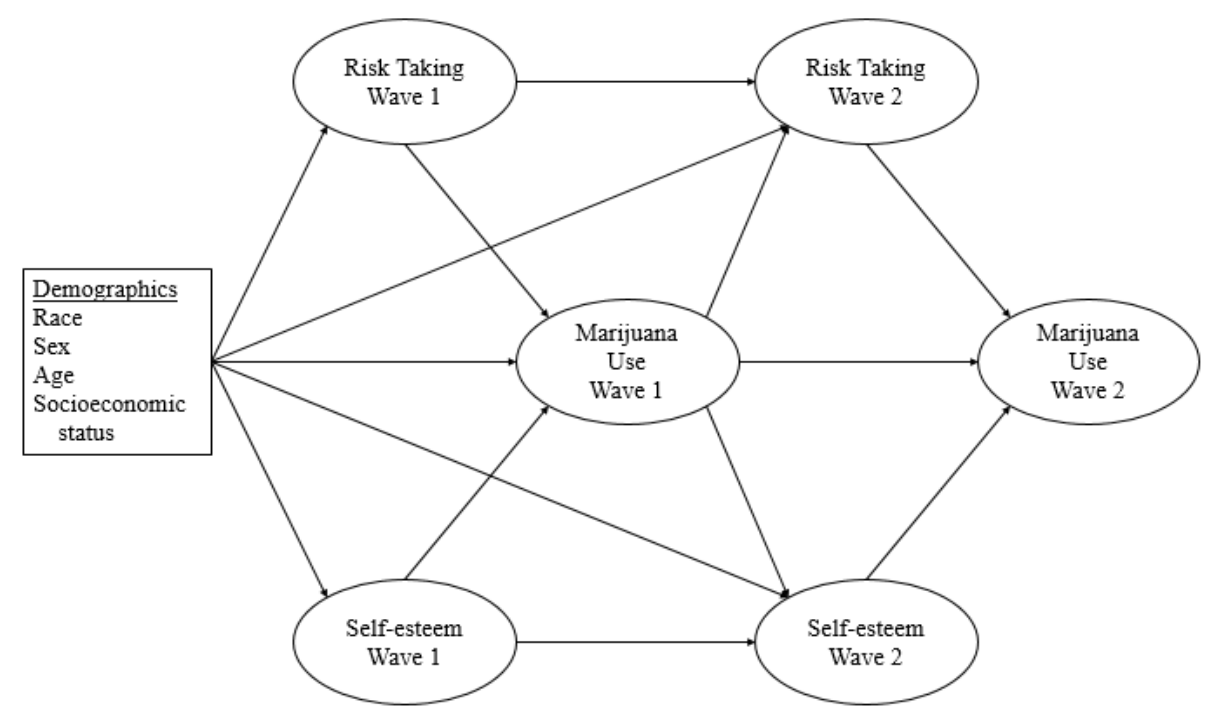

The fit indices of CFI, SRMR, and RMSEA all exceeded the standards required indicating a good fit of the model $(\mathrm{CFI}=0.975 ; \mathrm{SRMR}=0.041 ; \mathrm{RMSEA}=0.039)$. The $\chi^{2}$ measurement of model fit was significant $\left(\chi^{2}=2991.659, p<0.01\right)$, which again is expectedly due to the large sample size used in the analysis. The examination of the other three fit indices indicate that the model is a good fit to the data.

Standardized coefficients between the latent variables and the observed demographics are examined as an indication of the strength of the relationships between these variables. Table 6 gives the standardized coefficients for each of the relationships. Hypotheses 1-3 predict a direct effect between demographic variables and wave 1 latent constructs of risk taking, self-esteem, and marijuana use. Not being an African American was significantly related to risk taking in 1996 and 1998, but not related to self-esteem at either time point. Age was related to self-esteem at both time points, but only 
significantly related to risk-taking in 1998. Marijuana use in 1996 was significantly related to being a male, being Hispanic, and being older. The lack of significance in relations between demographic factors and latent variables across the two time points could be an indication of the widespread use of marijuana use across different socioeconomic status, genders, and race.

Table 7 Modified Longitudinal Structural Model Analysis

\begin{tabular}{|c|c|}
\hline Variable relationship & $\underline{\text { Standardized coefficient }}$ \\
\hline SES $\rightarrow$ Risk taking 1996 & 0.001 \\
\hline Males $\rightarrow$ Risk taking 1996 & 0.038 \\
\hline Hispanic $\rightarrow$ Risk taking 1996 & -0.006 \\
\hline African American $\rightarrow$ Risk Taking 1996 & $-0.134 * *$ \\
\hline Age $\rightarrow$ Risk taking 1996 & 0.017 \\
\hline SES $\rightarrow$ Self-esteem 1996 & 0.024 \\
\hline Males $\rightarrow$ Self-esteem 1996 & 0.003 \\
\hline Hispanic $\rightarrow$ Self-esteem 1996 & -0.027 \\
\hline African American $\rightarrow$ Self-esteem 1996 & 0.046 \\
\hline Age $\rightarrow$ Self-esteem 1996 & $0.098 * *$ \\
\hline $\mathrm{SES} \rightarrow$ Marijuana use 1996 & 0.039 \\
\hline Males $\rightarrow$ Marijuana use 1996 & $0.063 * *$ \\
\hline Hispanic $\rightarrow$ Marijuana use 1996 & $0.096 * *$ \\
\hline African American $\rightarrow$ Marijuana use 1996 & -0.066 \\
\hline Age $\rightarrow$ Marijuana use 1996 & $0.243 * *$ \\
\hline SES $\rightarrow$ Risk taking 1998 & -0.005 \\
\hline Males $\rightarrow$ Risk taking 1998 & 0.018 \\
\hline Hispanic $\rightarrow$ Risk taking 1998 & -0.025 \\
\hline African American $\rightarrow$ Risk taking 1998 & $-0.065 * *$ \\
\hline Age $\rightarrow$ Risk taking 1998 & $0.919 * *$ \\
\hline SES $\rightarrow$ Self-esteem 1998 & 0.009 \\
\hline Males $\rightarrow$ Self-esteem 1998 & 0.010 \\
\hline Hispanic $\rightarrow$ Self-esteem 1998 & -0.012 \\
\hline African American $\rightarrow$ Self-esteem 1998 & -0.001 \\
\hline Age $\rightarrow$ Self-esteem 1998 & $0.958 * *$ \\
\hline Risk taking $1996 \rightarrow$ Marijuana use 1996 & $0.296 * *$ \\
\hline Self-esteem $1996 \rightarrow$ Marijuana use 1996 & -0.029 \\
\hline Risk taking $1996 \rightarrow$ Risk taking 1998 & $0.091 * *$ \\
\hline Risk taking $1998 \rightarrow$ Marijuana use 1998 & $0.764 * *$ \\
\hline Marijuana use $1996 \rightarrow$ Risk taking 1998 & 0.018 \\
\hline Marijuana use $1996 \rightarrow$ Self-esteem 1998 & -0.011 \\
\hline
\end{tabular}




\section{Variable relationship Standardized coefficient}

Marijuana use $1996 \rightarrow$ Marijuana use 1998

Self-esteem $1996 \rightarrow$ Self-esteem 1998

Fit indices

Self-esteem $1996 \rightarrow$ Marijuana use 1998

$0.509 * *$

$0.170 * *$

$-0.302 * *$

\begin{tabular}{r|c}
$\chi^{2}$ & $2991.659 * *$ \\
CFI & 0.975 \\
SRMR & 0.041 \\
RMSEA & 0.039
\end{tabular}

Hypothesis 4, which predicts a significant relationship between risk taking and marijuana use, is supported in this analysis. Risk taking was significantly related to marijuana use at both the 1996 and the 1998 time frames. Hypothesis 7 predicts that there will be a strong relationship between self-esteem and marijuana use. Similar to the analysis in step 4, a significant relationship was found between self-esteem and marijuana use in 1998, but not in 1996. The influence of low self-esteem leading to marijuana use seen in 1998 but not in 1996 could be the result of changes in self-esteem over time or a relationship to the age of the sample. The change of self-esteem over time and its relationship to marijuana use is an unexplored topic in the criminal justice literature that could shed more light on the longitudinal trajectory of this relationship, but is outside the scope of this dissertation.

Hypotheses 5 and 6 predict an indirect relationship between demographic factors and marijuana use through self-esteem and risk taking. Table 7 shows the indirect effects of demographics on marijuana use through self-esteem and risk taking. Only the relationship between age and marijuana use through self-esteem and risk taking in the 1998 year was significant. This indirect relationship was not proposed in the original conceptualization of the nonsocial reinforcement theory by Wood and colleagues (1997). Wood and colleagues (1997) proposed that demographic factors would directly impact 
the deviant behavior which would then be reinforced by physiological and psychological rewards. The proposed extension of the theory in this dissertation by hypothesizing these relationships was not founded.

Hypotheses 8 and 9 in the current dissertation speculate that there will be an indirect relationship between self-esteem and risk taking through marijuana use. Table 8 shows the indirect relationships between risk taking and self-esteem in 1996 on their opposite reinforcer in 1998 through marijuana use in 1996. These nonsignificant coefficients indicate that self-esteem in 1996 does not impact propensity for risk taking in 1998 through marijuana use in 1996. Those who have low self-esteem and use marijuana, do not see an increase in their propensity to take risks in the future. Similarly, those with a high propensity for risk taking and use marijuana do not see a change in selfesteem in the future according to this data. Nonsignificant findings related to these two hypotheses do not support the reciprocal influences of nonsocial reinforcement proposed by Wood and colleagues (1997).

Table 8 Indirect Relationships of Nonsocial Reinforcement

\begin{tabular}{|c|c|c|}
\hline Demographic Variable relationships & 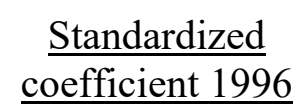 & 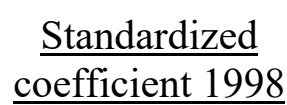 \\
\hline SES $\rightarrow$ Risk taking $\rightarrow$ Marijuana use & 0.000 & 0.004 \\
\hline Males $\rightarrow$ Risk taking $\rightarrow$ Marijuana use & 0.011 & -0.014 \\
\hline Hispanic $\rightarrow$ Risk taking $\rightarrow$ Marijuana use & -0.002 & 0.019 \\
\hline African American $\rightarrow$ Risk Taking $\rightarrow$ Marijuana use & -0.040 & 0.050 \\
\hline Age $\rightarrow$ Risk taking $\rightarrow$ Marijuana use & 0.005 & $-0.702 * *$ \\
\hline SES $\rightarrow$ Self-esteem $\rightarrow$ Marijuana use & -0.001 & -0.003 \\
\hline Males $\rightarrow$ Self-esteem $\rightarrow$ Marijuana use & 0.000 & -0.003 \\
\hline Hispanic $\rightarrow$ Self-esteem $\rightarrow$ Marijuana use & 0.001 & 0.004 \\
\hline $\begin{array}{r}\text { African American } \rightarrow \text { Self-esteem } \rightarrow \text { Marijuana } \\
\text { use }\end{array}$ & -0.001 & 0.000 \\
\hline Age $\rightarrow$ Self-esteem $\rightarrow$ Marijuana use & -0.003 & $-0.289 * *$ \\
\hline
\end{tabular}




\begin{tabular}{|c|c|c|}
\hline Demographic Variable relationships & $\begin{array}{l}\text { Standardized } \\
\text { coefficient } 1996\end{array}$ & $\begin{array}{l}\underline{\text { Standardized }} \\
\text { coefficient } 1998 \\
\end{array}$ \\
\hline $\begin{array}{r}\text { Self-esteem } 1996 \rightarrow \text { Marijuana use } \begin{array}{r}1996 \rightarrow \text { Risk } \\
\text { taking } 1998\end{array}\end{array}$ & -0.001 & \\
\hline 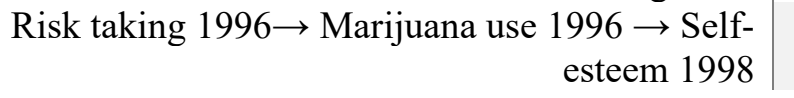 & -0.003 & \\
\hline
\end{tabular}

Hypotheses 10-12 suggest a connection between marijuana use at wave 1 and wave 2 measurements of risk-taking, risk taking, and self-esteem. Marijuana use in 1996 was not able to predict risk taking or self-esteem in 1998, but was significantly related to marijuana use in 1998. The main contribution of the current dissertation is this examination of reciprocal effects between behavior and nonsocial reinforces of psychological and physiological rewards. This reciprocal relationship is also present in hypotheses 13 and 14. As predicted, risk taking in 1998 and self-esteem in 1998 both have strong significant relationships with marijuana use in 1998. Individuals with low self-esteem who are high in risk taking are more likely to use marijuana, as predicted by Wood and colleagues (1997) nonsocial reinforcement theory.

The results from this analysis give some support to nonsocial reinforcement theory as proposed by Wood and colleagues (1997). The lack of significant relationships between marijuana use in 1996 and risk taking or self-esteem in 1998 does not allow for the confirmation of the reciprocal nature of nonsocial reinforcement. One possibility for this lack of support is the large time frame between the two measures. Two years may be too long that other rival causal factors influencing risk taking, self-esteem, and marijuana use are making the effects in the current study. Figure 6 gives the standardized coefficients and significance for the modified model allowing for an easier visual inspection of the relationships. Significant relationships between risk taking and selfesteem between the two time points examined, with insignificant relationships between 


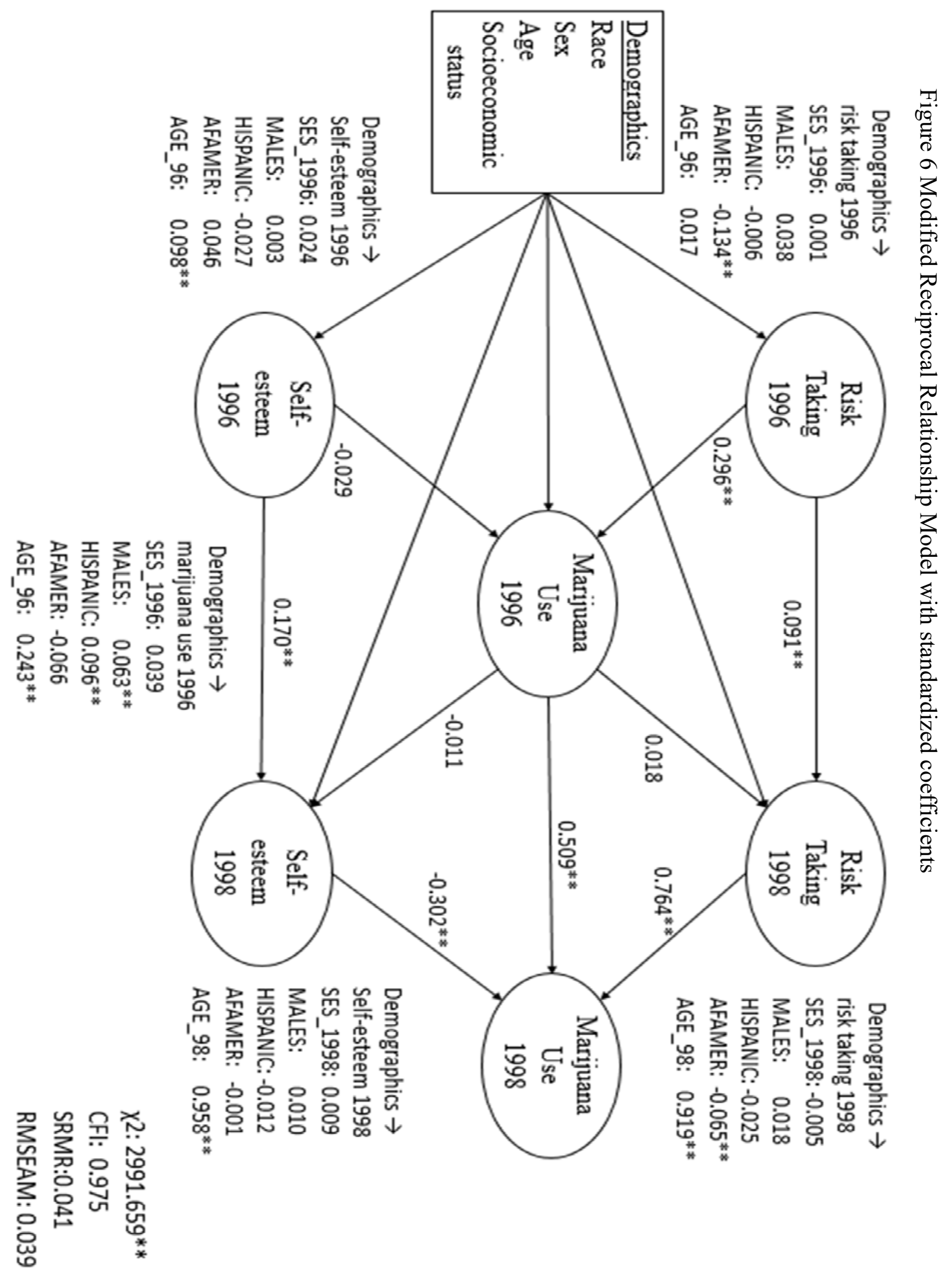


marijuana use at time one and risk taking and self-esteem at time two refute the reciprocal nature of nonsocial reinforcement.

This step can also serve as a multiple indicator multiple cause (MIMIC) model, which is used to examine the differences between groups (Muthen, 1989). While Wood and colleagues (1997) do not speculate that there would be a difference in the way in which nonsocial reinforcement influences different sexes, it is nevertheless important to examine this aspect in the current study to assure that results obtain are not simply an indication of differences in the sexes. Commonly CFA-based measurement models are utilized to examine measurement invariance (Meade \& Lautenschlager, 2004), however as Vandenberg (2002) points out, little is known about the psychometric properties of the series of tests suggested by Vandenberg and Lance (2000). Examination of some of the factors influencing the ability of CFA-based tests of measurement invariance has begun. Findings suggest that sample size and amount of variance explained in each variable can bias the results (Meade \& Lautenschlager, 2004). A metric determining the appropriate sample sizes and explained variance parameters in which this technique is most appropriate has not yet been determined (Meade \& Bauer, 2007). In fact, the same sample size performed differently in the various steps of measurement invariance advocated by Vandenberg and Lance (2000), indicating that conflicting results on these tests could be more of reflection of the psychometric properties of these tests than the actual invariance of the measurement (Meade \& Bauer, 2007). Due to these uncertainties, a MIMIC model was utilized to examine sex differences in nonsocial reinforcement. 
MIMIC models allows for the examination of covariance within a group as compared to another group in order to make a determination of the differences in measurement between the two groups (Muthen, 1989). Examining the paths between sex and the latent variables of nonsocial reinforcement examined in this dissertation, as given in table 7 , show that measurements of risk taking and self-esteem do not differ in either time point, indicating that measurement invariance does exist for those measurements and the sample can be considered homogenous. However, there is a significant relationship between marijuana use and sex. This indicates that there may be a difference in marijuana use between the sexes as predicted by nonsocial reinforcement. More research is needed to fully explore the differences between the sexes in predictions of nonsocial reinforcement.

Despite the lack of support for reciprocal findings, the significant influence of self-esteem and risk taking during the 1998 timeframe indicate that these factors do play a role in marijuana use, partially supporting the theory. This dissertation adds to the body of knowledge of the influence of nonsocial reinforcement on behavior. While the current analysis cannot support a longitudinal relationship, a cross-sectional relationship was found in the analysis. The evidence found for the connection between self-esteem and risk taking can be utilized in the design of interventions to prevent the use of marijuana and other deviant behavior.

\section{Summary}

The current dissertation used a five-step analysis in order to examine the reciprocal relationship between marijuana use and psychological and physiological 
rewards proposed by Wood and colleagues (1997). A confirmatory factor analysis supported the use of the observed variables as a measure of the latent variables of risk taking, self-esteem, and marijuana use at both waves of data collection. While fit indices showed that a modified version of the reciprocal model did fit the data, standardized coefficients showed that a reciprocal relationship between marijuana use and future selfesteem and risk taking were not supported. A single timeframe relationship between selfesteem, risk taking, and marijuana use supports that there is some influence of nonsocial reinforcement on behavior as proposed by Wood and colleagues (1997). Applications of nonsocial reinforcement in criminal justice along with implications of this dissertation's findings on the theory and limitations of the dissertation are discussed in the next chapter. 


\section{CHAPTER V \\ DISCUSSION}

\section{Overview}

The current dissertation sought to empirically test the hypothesized influence of nonsocial reinforcement on behavior. Wood and colleagues (1997) proposed that reinforcement from sources other than social rewards have an impact on behavior. Specifically, physiological and psychological rewards will reinforce behavior, causing the behavior to increase in frequency in the individual (Wood et al., 1997). Despite the growing empirical support for the theory, the theory is often tested using only a measure of risk taking (Higgins et al., 2011; Stevens et al., 2011), and the reciprocal nature of the theory has never been tested. The current dissertation tested that reciprocal relationship using two waves of the National Longitudinal Study of Youth 1979 Young Adult cohort (NLSY79-YA). Risk-taking was utilized as a measure of physiological rewards and selfesteem was utilized as a measure of psychological rewards in an examination of marijuana use. Results provide evidence for a cross-sectional, but not a longitudinal relationship of risk taking and self-esteem on marijuana use. The current findings lead to a better understanding of the limitations of the possible reciprocal effects from which behavior is reinforced. This knowledge can be utilized to create more effective programs to dissuade antisocial behavior and reinforce prosocial behavior, reducing crime and deviance. This chapter of the dissertation will discuss the implications of the findings, 
both for the theory and for the application of the theory to criminal justice practices and policies. Additionally, this chapter will suggest future research, discuss the limitations of the study, and provide concluding remarks of the overall importance of the current dissertation.

\section{Implications for Nonsocial Reinforcement Theory}

Findings from the current analysis provide support for the immediate impacts of Wood and colleagues (1997) nonsocial reinforcement theory, yet not a longitudinal influence. The theory suggests that behavior is reinforced through psychological and physiological rewards along with the commonly examined social reinforcement of behavior. In order to isolate the effects of nonsocial reinforcement, the influence of social reinforcement suggested in the theory was not tested in the current dissertation. The isolation of the influence of nonsocial rewards on behaviors tests a critical component of the theory which has not yet been explored. The hypotheses drawn from Wood and colleagues' (1997) specification of the model were partially confirmed in the current analysis. This empirical evidence for nonsocial reinforcement, while not reciprocal, still supports the use of nonsocial reinforcement as a means of predicting behavior. It is hypothesized that adding the influence of social reinforcement to the model will provide an even stronger predictor of behavior. This test of Wood and colleagues (1997) nonsocial reinforcement theory adds to our understanding of the means by which behavior is learned. With this additional knowledge, novel interventions can be created to break the forces influencing behavior. 
Previous studies examining the influence of nonsocial reinforcement have generally measured nonsocial reinforcement using a measure of risk taking (Harden, Quinn, \& Tucker-Drob, 2012; Harden \& Tucker-Drob, 2011). The results from the current dissertation are in line with previous results as a strong connection was seen between risk taking and marijuana use in a single timeframe. Wood and colleagues (1997) found that individuals more familiar with crime commission reported more positive feelings about the crime, indicating an increase in self-esteem resulting from the risky behavior of the crime. The current study is in line with these results as a connection was found between low levels of self-esteem and marijuana use during the second wave of data collection.

May (2003) found that adolescents engage in violent behavior for the thrill associated with the activity. The strong association between risk-taking and marijuana use at both time points examined in the current study agree with May's (2003) finding as taking the risks involved in marijuana use was seen as a rewarding behavior that helped to fuel subsequent use. Stevens and colleagues (2011) found that nonsocial reinforcement, as measured by a preference for risky activities, was associated with hard drug use in adolescents. The study suggested that juveniles may start using hard drugs due to nonsocial rewards, yet continual use may be the result of social reinforcement. Findings from the current dissertation show that nonsocial reinforcement of marijuana use continues to be associated with nonsocial rewards from self-esteem and risk-taking. Influences of social reinforcement were not tested in the current dissertation, but the evidence of the continued influence of nonsocial rewards two years after marijuana use 
suggest that the influences on nonsocial reinforcement, particularly risk taking, still have an influence on perpetual drug use.

In an exploration of nonsocial reinforcement theory in the abuse of prescription drugs, Higgins and colleagues (2009) found that their nonsocial reinforcement measure of risk-taking was not a significant predictor of sedative use. While nonsocial reinforcement was able to predict use of amphetamines and tranquilizers, the authors suspected that the lack of ability for their risk-taking measure to predict sedative use was the result of a lack of connection between the risk-seeking drives of individuals and the relaxing states created from sedatives (Higgins et al., 2009). Use of marijuana can produce feelings of relaxation similar to a sedative, and could be related to the methods of use of the drug (Block, Erwin, Farinpour, \& Braverman, 1998). Despite this sedation effect, the current study did find a connection between risk taking and marijuana use at both timeframes. One possible explanation for the differing results between the current study and the findings of Higgins and colleagues (2009) could be the age differences in the samples. The current dissertation examined the habits of individuals between the ages of 14 and 20 at the first wave of data collection, while Higgins and colleagues (2009) sample was composed mostly of young adults over the age of 18. In the current dissertation the participants may have derived excitement from the act of deviance that comes from the illegal act of using marijuana, regardless of the lack of stimulation that could be derived from the drug. Had Higgins and colleagues (2009) used a younger sample, it is possible that the nonsocial reinforcement element of risk-taking may become a significant predictor of sedative use. It is also possible that the study lacked a sufficient means of measuring nonsocial reinforcement. The model tested of nonsocial 
reinforcement predicting sedative use did find that peer influences were able to predict sedative use (Higgins et al., 2009). Should the study have included a measure of selfesteem, it is possible that the two elements of nonsocial reinforcement of social status and self-esteem could have predicted sedative use in the sample, supporting nonsocial reinforcement theory.

The current dissertation partially supports Wood and colleagues (1997) nonsocial reinforcement theory. Findings show that psychological rewards of increases in selfesteem and physiological rewards of increased risk-taking are associated with marijuana use. The analysis failed to find support for a longitudinal relationship over a two-year time frame. The influences of reinforcement are strongest at shorter timeframes, and the two-year interval here may be too long to detect these influences.

The isolation of psychological and physiological reinforcement in the current study provide important evidence supporting the model of nonsocial reinforcement. The theory helps to understand how behavior is learned and what factors influence behavior. With this improved understanding of behavior, better, more effective interventions can be created in order to help maintain prosocial behavior. More effective interventions will lead to a reduction in criminal behavior, a major goal for the field of criminal justice.

\section{Implications for Criminal Justice}

The current dissertation has added to the knowledge of nonsocial reinforcement theory as proposed by Wood and colleagues (1997). The influence of nonsocial reinforcement over behavior can be utilized as a key element in interventions geared at changing behavior. Interventions based on these finds supporting nonsocial 
reinforcement can help reduce deviant behaviors, reducing crime. School-based interventions are a major attempt at dissuading adolescents from drug use. Media campaigns are also utilized to reach a wide audience of youth and communicate the dangers of drug use. The evidence supporting nonsocial reinforcement theory obtained from this dissertation provides new information about behavior. The influence of psychological and physiological rewards on behavior can be utilized in these efforts to dissuade drug use.

Two main strategies utilized in order to deter youth from drug use are schoolbased intervention programs and large scale media campaigns. Much research has gone into understanding what program features of school-based interventions show better results than others. It is acknowledged that the generalizability of these programs is problematic as different features of a program may show promise in one study, a different study with a different program but same program feature may not be effective (Cuijpers, 2002). Despite this limitation of analyses, studies examining features of effective programs find that interactive programs that allow for a sharing of ideas rather than lecture-style courses are more effective (Cuijpers, 2002; Soole, Mazerolle, \& Rombouts, 2008; Tobler et al., 2000). Several studies have found that a social influence model is conducive of effective programs. Widespread evidence has also been found for the utilization of social influence techniques which teach resistance skills, life skills, and blocking the normalization of drug use by dispelling the myth that many of the youth's peers are using drugs (Cuijpers, 2002; Hansen 1993; Tobler et al., 2000).

May studies have found conflicting evidence for different elements of programs. For example, the use of booster sessions to reinforce the lessons of the program and 
prolong the effects the program were found to be effecting in some meta-analyses (McBride, 2003) and ineffective in other analyses (Cuijpers, 2002; Soole et al., 2008). The effect of program intensity on effectiveness of the program has been conflicted in the literature, with some studies showing that longer programs are more effective (Soole et al., 2008; Toblar et al., 2000) and others showing that program length is not significantly related to achievement of program goals (Cuijpers, 2002). Literature also conflicts on the use of programs targeted to the specific needs of the individuals in the program (McBride, 2003) or universal programs being the most effective (Soole et al., 2008). This conflicting evidence of the mechanisms that produce the most favorable results in prevention programs suggest that we still are not sure of the logic model through which behavior is learned. One effective model of handling substance abuse has been found in Iceland. The Icelandic Model of Adolescent Substance Use Prevention utilized the efforts of local communities to support parents, enforce curfews, and create a network of schools and after-school activities. Schools helped to link students with prosocial activities such as sports (Sigfúsdóttir, Thorlindsson, Kristjánsson, Roe, \& Allegrante, 2009). Sports activities could serve as a means to satisfy the adolescent's thirst for physiological rewards. Sports activities have also been found to improve an individual's self-esteem, satisfying the psychological rewards that this dissertation and other research has shown can help drive substance use. More models similar to this approach that address the adolescent's need for psychological rewards and physiological stimulation are expected to be more efficient in reducing substance use.

A new field of research examining prosocial risk taking has emerged. This field looks at how risky decisions are made by individuals with the goal of helping others (Do, 
Moreira, \& Telzer, 2016). In adolescence, the risky behavior can often be associated with social interactions. For example, standing up for a peer that is being bullied is a prosocial behavior, yet is socially risky as it exposes the individual to possible social ramifications such as alienation from the group (Do, Moreira, \& Telser, 2016). More research into the factors associated with prosocial risk taking could help translate adolescent risk taking propensity away from deviant behaviors in favor of altruistic goals.

A propensity for risk taking can be satisfied with interventions that simulate risky situations. A competition among students in a mock stock trading scenario may be able to satisfy risk-seekers drives (Holton, 2004). Activities like amusement park roller coasters, skydiving, and bungee jumping could also help satisfy risk seekers while avoiding deviant behavior.

Previous studies have found that participation in endurance sports during adolescence was associated with lower levels of alcohol, tobacco and marijuana use later in life (Wichstrom \& Wichstrom 2009). Additionally, participation in sports has been found to increase self-esteem (Bowker, Gadbois, \& Cornock, 2003). An increase in selfesteem and satisfaction of risk-taking gained from participation in sports is theorized by Wood and colleagues (1997) nonsocial reinforcement theory to reduce deviant behavior. Encouragement of sports participation for adolescents and young adults and a means of connecting these individuals to sporting activities that interest them could lead to reduced deviance.

Media campaigns are another major means of dissuading individuals from drug use. One study examining specific reactions by individuals to a variety of public service announcements (PSA) in a laboratory setting found that framing of the message and an 
evaluation of threat were the main factors contributing to the effectiveness of the message. Overall results of the study found that PSA messages were generally successful in increasing reported awareness of consequences of marijuana use and in reducing favorable attitudes towards marijuana use over a control message (Zimmerman et al., 2014). The effect of PSAs found in this study may be short-lived, or may not translate into the real world. A nationally representative sample of youth was used to examine the connection between exposure to PSAs and marijuana use across four time periods. While there was generally no relationship between PSA exposure and marijuana use, some evidence was found to indicate a negative effect of PSAs on drug use. One round of analysis found that increased exposure to PSAs lead to higher reports of intent to use marijuana (Hornik, Jacobsohn, Orwin, Piesse, \& Kalton, 2008). Zimmerman and colleagues (2014) found that PSAs focused more on losses resulting from drug use rather than gains of being drug-free and higher levels of threats in the message resulted in more unfavorable views towards marijuana. It is expected that PSAs that focus on the prosocial risk-taking activities that can be performed when not under the influence of drugs would have a stronger effect on perceptions of drug use. The connection this dissertation shows between risk-taking, self-esteem, and marijuana use demonstrates the need for these drives of substance use to be included in efforts to dissuade use.

\section{Future Research}

Findings from this dissertation provide support for the use of nonsocial reinforcement theory in understanding human behavior and designing interventions to 
reduce marijuana use. This dissertation is merely the start of a long line of possible research examining the empirical evidence supporting nonsocial reinforcement theory. Future studies should include all aspects of nonsocial reinforcement theory, examine behaviors beyond marijuana use, with other data sources, other age groups and samples, and using various measurements over time.

The current dissertation isolated the effects of psychological and physiological rewards on behavior in order to examine their influence in behavior. Future studies should expand on the evidence supporting nonsocial reinforcement by examining the full nonsocial reinforcement model. The model as originally conceptualized by Wood and colleagues (1997) includes the influence of exogenous rewards of behavior that include material gains and social benefits. An examination of these additional influences on the nonsocial reinforcement model would further strengthen the evidence for the theory. While social influences and material gains from deviant behavior have been previously studied, the incorporation of all aspects of nonsocial reinforcement theory will give a better understanding of how each of the variables work together to influence behavior.

The current dissertation only examined the influences of nonsocial reinforcement on marijuana use. In order to confirm the theory can predict a wide range of deviant behavior, more research is needed examining various behaviors. Different deviant behaviors have differing influences that drive the behavior. In order for nonsocial reinforcement theory to be the general theory of deviant behavior proposed by Wood and colleagues (1997) there must be empirical support of its broad range of predictive abilities. Previous studies of nonsocial reinforcement theory have utilized a measure of risk taking as a means of testing the theory (Harden, Quinn, \& Tucker-Drob, 2012; 
Harden \& Tucker-Drob, 2011). Tests of the theory that include more elements of the theory examined over broad ranges of behavior will provide necessary evidence for the theory's broad application.

Replication of results is a necessity in all research. The current dissertation tested the hypotheses of nonsocial reinforcement theory on one dataset across two years of data collection. Future tests of the theory should attempt to replicate the results obtained in the current analysis using other datasets, other means of sampling, and other age groups. These replications can help identify weaknesses in the theory and provide evidence for any misspecification of the model that may need to be addressed. This replication will also serve to reinforce the results obtained in this dissertation. Through this continued research we will be able to understand more about how behavior is learned and perpetuated. This knowledge will help to dissuade individuals from antisocial behavior and break the cycle of rewards that reinforce negative behaviors.

In order to test the reciprocal effects of nonsocial reinforcement theory it was necessary to use longitudinal data for the current analysis. A two-year time frame was utilized in order to examine the reciprocal effects. Results of the current dissertation show that two years cannot provide sufficient evidence for the reciprocal influence of nonsocial reinforcement. Future studies should use longer and shorter time frames between measurements to examine the impact of time in the reinforcement of behavior. Multiple time points, beyond just two, should be utilized to examine changes in behavior over time. This additional research will provide more evidence of the predictive scope of nonsocial reinforcement. 
Risk denial theory, as proposed by Pretti-Watel (2003), suggests that individuals who engage in risky behavior, such as marijuana use, must find a way to neutralize the negative social stigma associated with the risk behavior. Strategies found for neutralizing the risk of marijuana use include users claiming they can control their use, equating marijuana with other legal drugs like alcohol, and blaming incorrect generalizations of hard drug use for misconceptions about marijuana (Pretti-Watel, 2003). This dissertation's evidence of the influence of risk-taking as a physiological reward reinforcing behavior indicates that risk is a motivating factor that influences the use of marijuana. While some cognitive dissonance may occur in the risk-taking individual using marijuana, the drive to take risks and the physiological rewards of risky behaviors like marijuana use may actually be driving use. More research is needed to further understand the influences of risk denial theory in light of nonsocial reinforcement theory to determine which has a more substantial influence on behavior and the limits of these influences.

The research suggested above would provide necessary information about the limits and specifications of nonsocial reinforcement theory. This research could lead to new and unexpected hypotheses to be tested in an effort to better understand behavior. With a thorough knowledge of the factors influencing behavior, better interventions can be created to dissuade deviant behavior. The use of empirical evidence in testing criminological theories to understand behavior allows for more effective strategies at reducing offending. 


\section{Limitations}

There are several limitations of this dissertation that must be acknowledged. Limitations in the current study include limitations of the data utilized, limits with isolating the influences of nonsocial reinforcers, and limits with our knowledge of marijuana use. While these limitations are minor, it is important to acknowledge these limitations which can impact the certainty of the results of the current analysis.

The current study utilized a secondary dataset obtained through self-report measures. The population from which the sample was derived was the children of those who participated in the National Longitudinal Study of Youth 1979. While this original sample was considered a representative sample of the US at the time, the children of this sample cannot be considered a completely representative sample. Any changes to the population between when the sample was derived in 1979 and the start of the first observation in the current study in 1996 may not be reflected. This may limit the generalizability of the results obtained in this dissertation. While the sample may not be truly representative, it should still be a general approximation of the population of the United states. Another limitation of the dataset utilized for the analysis is the reliance on self-report. Self-report of behaviors that are not socially favorable, such as marijuana use, may not be accurately reported. There is some empirical evidence that self-report is a valid means of collecting information about marijuana use (Aguinis, Pierce, \& Quigley, 1995). The measurement of race available in the current dataset is limited to an examination of African Americans and Hispanics in comparison to all other races. Ideally, in order to isolate the impacts of minority status, variables that allow for the comparison between minorities and whites would give a more accurate indication of the 
imapct of race. Despite the limitations of the race information available in the dataset, race was still utilized in the study as Wood and colleagues (1997) proposed it would have an impact in nonsocial reinforcement theory.

Another limitation of the data is the timeframes in which data is collected. Ideally a more recent time frame for data collection would have been utilized to get a better understanding of the influence of nonsocial reinforcement in the current social climate of marijuana use. Limitations of funding resulted in data for this cohort to be collected only every four years, which was thought to be too far of a time frame for the examination of reinforcement of behavior. Funding also limited the questions asked of participants during more recent data collections. Questions regarding marijuana use were reduced in number, which resulted in only two categorical variables assessing the measure. The use of strucutral equation modeling with latent variables requires the latent variable to be identified with at least three observed variables (Rigdon, 1995). A dichotomous variable of marijuana use collected during the 2002, 2004, and 2008 years was attempted in the analysis in place of the no longer collected variable regarding lifetime marijuana use. The analysis would not produce stable results due to the lack of variance in the available data.

The current dissertation isolated the effects of nonsocial rewards of risk-taking and self-esteem. This limits the conclusions that can be drawn about nonsocial reinforcement theory in general. Wood and colleagues (1997) originally conceptualized the theory to include exogenous rewards of social status and instrumental rewards. As these elements of the theory were not tested in the current analysis, this dissertation serves as a partial test of nonsocial reinforcement theory. Evidence suggests that the 
differing influences from social and nonsocial reinforcement on behavior may be intricately intertwined and inseparable. In a longitudinal study of public high school students, Brezina and Piquero (2003) found that peer norms and individual definitions favorable to use, both considered social reinforcement, influenced the amount of pleasure an individual reported experiencing from the use of marijuana or alcohol. This connection of social and nonsocial reinforcement makes it difficult to isolate and control for these streams of influence. It is possible that the results of the current analysis are still influenced by the social rewards of the behavior as they impact the perceived nonsocial rewards.

Limits on conducting research on marijuana due to its Schedule I status means that we have not explored all the possible consequences of marijuana use. Temple, Brown and Hine (2011) identified four gaps in our knowledge about marijuana use. First, the connection between use and negative outcomes needs to be further explored. Second, the likelihood of users experiencing these negative outcomes is not well understood. The impact (thirdly) and the severity (fourthly) that these negative outcomes could have on the user's ability to function in everyday life has been largely unexplored (Temple, Brown, \& Hine, 2011). Despite these limitations, the current study provides evidence supporting the continued examination of Wood and colleagues (1997) nonsocial reinforcement theory in order to better understand behavior.

\section{Conclusions}

In conclusion, the current dissertation adds to our body of knowable about human behavior by testing the nonsocial reinforcement of behavior proposed by Wood and 
colleagues (1997) in nonsocial reinforcement theory. Results indicate that psychological and physiological rewards can influence behavior. While the results from the current analysis do not support the reciprocal nature of nonsocial reinforcement across a two-year time frame, the connection between risk taking and self-esteem on marijuana use is sufficient to warrant further examination. The knowledge gained from this understanding of the influences reinforcing behavior allows for a deeper understanding of antisocial behavior. With this increased knowledge, interventions can be created to help break this cycle of reinforcement to help individuals desist from antisocial behavior. While more research is needed to fully understand the influences of nonsocial reinforcement on behavior, the current dissertation is an important step in our understanding of behavior. 


\section{REFERENCES}

Aguinis, H., Pierce, C. A., \& Quigley, B. M. (1995). Enhancing the Validity of SelfReported Alcohol and Marijuana Consumption Using a Bogus Pipeline Procedure: A Meta-Analytic Review. Basic \& Applied Social Psychology, 16(4), $515-527$.

Akers, R. L. (1985). Deviant Behavior: A Social Learning Approach (3 ed.). Belmont, CA: Wadsworth.

Akers, R. L. (1994). Criminological Theories: Introduction and Evaluation. Los Angeles, CA: Roxbury.

Akers, R. L. (1998). Social Learning and Social Structure: A General Theory of Crime and Deviance. Boston, MA: Northeastern University Press.

Akers, R. L., \& Cochran, J. K. (1985). Adolescent marijuana use: A test of three theories of deviant behavior. Deviant Behavior, 6(4), 323-346.

Akers, R. L., \& Jensen, G. F. (2006). The empirical status of social learning theory of crime and deviance: The past, present, and future. Taking stock: The status of criminological theory, 15, 37-76.

Akers, R. L., Krohn, M. D., Lanza-Kaduce, L., \& Radosevich, M. (1979). Social learning and deviant behavior: A specific test of a general theory. American Sociological Review, 636-655. 
Azofeifa, A., Mattson, M., Schauer, G., McAfee, T., Grant, A., \& Lyerla, R. (2016). National Estimates of Marijuana Use and Related Indicators — National Survey on Drug Use and Health, United States, 2002-2014. . (No. SS-11). MMWR Surveill Summ.

Bagley, C., Bolitho, F., \& Bertrand, L. (2007). Norms and construct validity of the Rosenberg Self-Esteem Scale in Canadian high school populations: Implications for counselling. Canadian Journal of Counselling and Psychotherapy/Revue canadienne de counseling et de psychothérapie, 31(1).

Bender, S. W. (2016). The Colors of Cannabis: Race and Marijuana. UCDL Rev., 50, 689-706.

Bentler, P. M., \& Bonett, D. G. (1980). Significance tests and goodness of fit in the analysis of covariance structures. Psychological bulletin, 88(3), 588.

Berry, W. D., \& Feldman, S. (1985). Multiple regression in practice (No. 50). New York: Sage.

Blevins, C. E., Banes, K. E., Stephens, R. S., Walker, D. D., \& Roffman, R. A. (2016). Motives for marijuana use among heavy-using high school students: An analysis of structure and utility of the Comprehensive Marijuana Motives Questionnaire. Addictive behaviors, 57, 42-47. doi:10.1016/j.addbeh.2016.02.005

Block, R. I., Erwin, W. J., Farinpour, R., \& Braverman, K. (1998). Sedative, stimulant, and other subjective effects of marijuana: relationships to smoking techniques. Pharmacology Biochemistry and Behavior, 59(2), 405-412.Bowker, A., Gadbois, S., \& Cornock, B. (2003). Sports participation and self-esteem: Variations as a function of gender and gender role orientation. Sex roles, 49(1), 47-58. 
Brauer, J. R. (2009). Testing social learning theory using reinforcement's residue: A multilevel analysis of self-reported theft and marijuana use in the national youth survey. Criminology, 47(3), 929-970.

Brezina, T., \& Aragones, A. A. (2004). Devils in disguise: The contribution of positive labeling to "sneaky thrills" delinquency. Deviant behavior, 25(6), 513-535.

Brezina, T., \& Piquero, A. R. (2003). Exploring the relationship between social and nonsocial reinforcement in the context of social learning theory. In R. L. Akers \& G.F. Jensen (Eds.), Social learning theory and the explanation of crime: A guide for the new century. Advances in criminological theory (Vol. 11, pp. 265-288). New Brunswick, N.J.: Transaction Publishers.

Brezina, T., \& Topalli, V. (2012). Criminal self-efficacy exploring the correlates and consequences of a "successful criminal" identity. Criminal Justice and Behavior, 39(8), 1042-1062.

Brook, J. S., Balka, E. B., \& Whiteman, M. (1999). The risks for late adolescence of early adolescent marijuana use. American Journal of Public Health, 89(10), 15491554.

Bureau of Labor Statistics. (n.d.). National longitudinal survey of youth 1979 children and young adults. Retrived from https://www.nlsinfo.org/content/cohorts/nlsy79children/intro-to-the-sample/nlsy79-childyoung-adult-sample-introduction

Burgess, R. L., \& Akers, R. L. (1966). A differential association-reinforcement theory of criminal behavior. Social problems, 14(2), 128-147. 
Burkett, S. R., \& Jensen, E. L. (1975). Conventional Ties, Peer Influence, and the Fear of Apprehension: a Study of Adolescent Marijuana Use. Sociological Quarterly, $16(4), 522-533$.

Burkett, S. R., \& Warren, B. O. (1987). Religiosity, peer associations, and adolescent marijuana use: A panel study of underlying causal structures. Criminology, 25(1), 109-132.

Center for Behavioral Health Statistics and Quality. (2015). Behavioral health trends in the United States: Results from the 2014 National Survey on Drug Use and Health. (HHS Publication No. SMA 15-4927, NSDUH Series H-50). Retrieved from http://www.samhsa.gov/data/.

Common Sense for Drug Policy. (2007). Drug War Facts. Retrieved from http://www.drugwarfacts.org/factbook.pdf

Cooper, K., May, D., Soderstrom, I., \& Jarjoura, G. R. (2009). Examining Theoretical Predictors of Substance Use Among a Sample of Incarcerated Youth. Journal of Offender Rehabilitation, 48(8), 669-695. doi:10.1080/10509670903287675

Cuijpers, P. (2002). Effective ingredients of school-based drug prevention programs: A systematic review. Addictive behaviors, 27(6), 1009-1023.

Dembo, R., Grandon, G., Voie, L. L., Schmeidler, J., \& Burgos, W. (1986). Parents and drugs revisited: Some further evidence in support of social learning theory. Criminology, 24(1), 85-104.

Derzon, J. H., \& Lipsey, M. W. (1999). A Synthesis of the Relationship of Marijuana Use with Delinquent and Problem Behaviors. School Psychology International, 20(1), 57. 
Dielman, T., Campanelli, P. C., Shope, J. T., \& Butchart, A. T. (1987). Susceptibility to peer pressure, self-esteem, and health locus of control as correlates of adolescent substance abuse. Health Education \& Behavior, 14(2), 207-221.

Dishion, T. J., Capaldi, D., Spracklen, K. M., \& Li, F. (1995). Peer ecology of male adolescent drug use. Development and Psychopathology, 7(04), 803-824.

Do, K. T., Moreira, J. F. G., \& Telzer, E. H. (2016). But is helping you worth the risk? Defining Prosocial Risk Taking in adolescence. Developmental Cognitive Neuroscience. https://doi.org/10.1016/j.dcn.2016.11.008

Donnellan, M. B., Ackerman, R. A., \& Brecheen, C. (2016). Extending Structural Analyses of the Rosenberg Self-Esteem Scale to Consider Criterion-Related Validity: Can Composite Self-Esteem Scores Be Good Enough? Journal of Personality Assessment, 98(2), 169-177. doi:10.1080/00223891.2015.1058268

Drug Enforcement Administration. (2015). Drugs of Abuse: A DEA Resource Guide. Retrieved from https://www.dea.gov/pr/multimedialibrary/publications/drug_of_abuse.pdf\#page $=72$

Drug Enforcement Administration. (n.d.). Drug Scheduling. Retrieved from https://www.dea.gov/druginfo/ds.shtml

Ehrenreich, H., Rinn, T., Kunert, H. J., Moeller, M. R., Poser, W., Schilling, L., ... \& Hoehe, M. R. (1999). Specific attentional dysfunction in adults following early start of cannabis use. Psychopharmacology, 142(3), 295-301.

Ellis, L. (1987). Religiosity and criminality from the perspective of arousal theory. Journal of Research in Crime and Delinquency, 24(3), 215-232. 
Enders, C. K., \& Bandalos, D. L. (2001). The relative performance of full information maximum likelihood estimation for missing data in structural equation models. Structural Equation Modeling, 8(3), 430-457.

Fergusson, D. M., \& Horwood, L. (1997). Early onset cannabis use and psychosocial adjustment in young adults. Addiction, 92(3), 279-296.

Fried, P., Watkinson, B., James, D., \& Gray, R. (2002). Current and former marijuana use: preliminary findings of a longitudinal study of effects on IQ in young adults. Canadian Medical Association Journal, 166(7), 887-891.

Galliher, R. V., Evans, C. M., \& Weiser, D. (2007). Social and individual predictors of substance use for Native American youth. Journal of Child \& Adolescent Substance Abuse, 16(3), 1-16.

George, D. \& Mallery, P. (2006). SPSS for windows step by step: A simple study guide and reference, 13.0 update, 6th Edition. Boston, MA:Pearson Education Inc.

Grant, I., Gonzalez, R., Carey, C. L., Natarajan, L., \& Wolfson, T. (2003). Non-acute (residual) neurocognitive effects of cannabis use: a meta-analytic study. Journal of the International Neuropsychological Society, 9(05), 679-689.

Gray-Little, B., Williams, V. S. L., \& Hancock, T. D. (1997). An item response theory analysis of the Rosenberg Self-Esteem Scale. Personality and Social Psychology Bulletin, 23, 443-451.

Hagan, F. E. (1997). Research methods in criminal justice and criminology ( $8^{\text {th }}$ ed.). C. Romano, \& A. Nollkaemper (Eds.). Boston: Allyn and Bacon.

Hansen, W. B. (1993). School-based alcohol prevention programs. Alcohol Health \& Research World, 17(1), 54 
Harden, K. P., Quinn, P. D., \& Tucker-Drob, E. M. (2012). Genetically influenced change in sensation seeking drives the rise of delinquent behavior during adolescence. Developmental science, 15(1), 150-163.

Harden, K. P., \& Tucker-Drob, E. M. (2011). Individual differences in the development of sensation seeking and impulsivity during adolescence: further evidence for a dual systems model. Developmental psychology, 47(3), 739.

Hays, R. D., \& Ellickson, P. L. (1990). How generalizable are adolescents' beliefs about pro-drug pressures and resistance self-efficacy? Journal of Applied Social Psychology, 20(4, Pt 1), 321-340. doi:10.1111/j.1559-1816.1990.tb00414.x

Higgins, G. E., Jennings, W. G., Marcum, C. D., Ricketts, M. L., \& Mahoney, M. (2011). Developmental trajectories of nonsocial reinforcement and offending in adolescence and young adulthood: An exploratory study of an understudied part of social learning theory. Journal of Criminal Justice, 39(1), 60-66.

Higgins, G. E., Mahoney, M., \& Ricketts, M. L. (2009). Nonsocial Reinforcement of the Nonmedical use of Prescription Drugs: A partial test of social learning andd selfcontrol theories. Journal of drug issues, 39(4), 949-963.

Holton, G. A. (2004). Defining risk. Financial Analysts Journal, 60(6), 19-25.

Hornik, R., Jacobsohn, L., Orwin, R., Piesse, A., \& Kalton, G. (2008). Effects of the National Youth Anti-drug Media Campaign on youths. American Journal Of Public Health, 98(12), 2229-2236. doi:10.2105/AJPH.2007.125849

Imtiaz, S., Shield, K. D., Roerecke, M., Cheng, J., Popova, S., Kurdyak, P., . . Rehm, J. (2016). The burden of disease attributable to cannabis use in Canada in 2012. Addiction, 111(4), 653-662. doi:10.1111/add.13237 
Inciardi, J. A. (2002). The war on drugs III: The continuing saga of the mysteries and miseries of intoxication, addiction, crime, and public policy. Boston, MA.: Pearson/Allyn and Bacon.

Jarjoura, G. R., \& May, D. C. (2000). Integrating criminological theories to explain violent forms of delinquency. Caribbean Journal of Criminology and Social Psychology, 5(1-2), 81-102.

Johnson, R. E., Marcos, A. C., \& Bahr, S. J. (1987). The role of peers in the complex etiology of adolescent drug use. Criminology, 25(2), 323-340.

Kaplan, H. B., Martin, S. S., \& Robbins, C. (1984). Pathways to adolescent drug use: Self-derogation, peer influence, weakening of social controls, and early substance use. Journal of Health and Social Behavior, 270-289.

Khatapoush, S., \& Hallfors, D. (2004). "Sending the wrong message": did medical marijuana legalization in California change attitudes about and use of marijuana? Journal of drug issues, 34(4), 751-770.

Kline, R. B. (1998). Principles and Practices of Structural Equation Modeling. New York: The Guildford Press.

Krohn, M. D., Skinner, W. F., Massey, J. L., \& Akers, R. L. (1985). Social learning theory and adolescent cigarette smoking: A longitudinal study. Social problems, 32(5), 455-473.

Lee, G., Akers, R. L., \& Borg, M. J. (2004). Social Learning and Structural Factors in Adolescent Substance Use. Western Criminology Review, 5(1), 17-34. 
Li, C., Pentz, M. A., \& Chou, C.-P. (2002). Parental substance use as a modifier of adolescent substance use risk. Addiction, 97(12), 1537-1550. doi:10.1046/j.13600443.2002.00238.x

Lyng, S. (1990). Edgework: A social psychological analysis of voluntary risk taking. American journal of sociology, 851-886.

Lynskey, M., \& Hall, W. (2000). The effects of adolescent cannabis use on educational attainment: a review. Addiction, 95(11), 1621-1630.

Malmberg, M., Overbeek, G., Vermulst, A. A., Monshouwer, K., Vollebergh, W. A. M., \& Engels, R. C. M. E. (2012). The theory of planned behavior: Precursors of marijuana use in early adolescence? Drug and Alcohol Dependence, 123(1-3), 2228. doi:10.1016/j.drugalcdep.2011.10.011

Mann, F. D., Patterson, M. W., Grotzinger, A. D., Tackett, J. L., Kretsch, N., TuckerDrob, E. M., \& Harden, K. P. (2016). Sensation seeking, peer deviance, and genetic influences on adolescent delinquency: Evidence for person-environment correlation and interaction. Journal of Abnormal Psychology, 125(5), 679-691. doi:10.1037/abn0000160

May, D. C. (2003). Nonsocial reinforcement and violence: Can juvenile justice policies be effective against intrinsic gratification received from violent activity among youth? Journal for Juvenile Justice \& Detention Services, 18(1).

McBride, N. (2003). A systematic review of school drug education. Health education research, 18(6), 729-742.

Meade, A. W., \& Bauer, D. J. (2007). Power and precision in confirmatory factor analytic tests of measurement invariance. Structural Equation Modeling, 14(4), 611-635. 
Meade, A. W., \& Lautenschlager, G. J. (2004). A Monte-Carlo study of confirmatory factor analytic tests of measurement equivalence/invariance. Structural Equation Modeling, 11(1), 60-72.

Meneses, R. A., \& Akers, R. L. (2011). A comparison of four general theories of crime and deviance marijuana use among American and Bolivian university students. International Criminal Justice Review, 21(4), 333-352.

Meshesha, L. Z., Dennhardt, A. A., \& Murphy, J. G. (2015). Polysubstance Use Is Associated With Deficits in Substance-Free Reinforcement in College Students. Journal of Studies on Alcohol \& Drugs, 76(1), 106-116.

Millhorn, M., Monaghan, M., Montero, D., Reyes, M., Roman, T., Tollasken, R., \& Walls, B. (2009). North Americans' attitudes toward illegal drugs. Journal of Human Behavior in the Social Environment, 19(2), 125-141.

Miron, J. A. (2005). The budgetary implications of marijuana prohibition: Marijuana Policy Project.

Moore, S., \& Laflin, M. T. (1996). The role of cultural norms in the self-esteem and drug use relationship. Adolescence, 31(123), 523.

Moore, T. M., Stuart, G. L., \& Meehan, J. C. (2008). Drug abuse and aggression between intimate partners: A meta-analytic review. Clinical Psychology Review, 28(2), $248-275$.

Moran, T. J. (2010). Just a Little Bit of History Repeating: The California Model of Marijuana Legalization and How it Might Affect Racial and Ethnic Minorities. Wash. \& Lee J. Civil Rts. \& Soc. Just., 17, 557. 
Mui, H. Z., Sales, P., \& Murphy, S. (2013). Everybody’s doing it: Initiation to prescription drug misuse. Journal of drug issues, 0022042613497935.

Muthén, B. O. (1989). Latent variable modeling in heterogeneous populations. Psychometrika, 54(4), 557-585.

Olsson, U., Drasgow, F., \& Dorans, N. J. (1982). The polyserial correlation coefficient. Psychometrika, 47(3), 337-347.

Patton, G. C., Coffey, C., Lynskey, M. T., Reid, S., Hemphill, S., Carlin, J. B., \& Hall, W. (2007). Trajectories of adolescent alcohol and cannabis use into young adulthood. Addiction, 102(4), 607-615.

Pope, H. G., \& Yurgelun-Todd, D. (1996). The residual cognitive effects of heavy marijuana use in college students. JAMA, 275(7), 521-527.

Pratt, T. C., Cullen, F. T., Sellers, C. S., Thomas Winfree Jr, L., Madensen, T. D., Daigle, L. E., .. . Gau, J. M. (2010). The empirical status of social learning theory: A meta-analysis. Justice Quarterly, 27(6), 765-802.

Peretti-Watel, P. (2003). Neutralization theory and the denial of risk: Some evidence from cannabis use among French adolescents. The British journal of sociology, 54(1), 21-42.

Raykov, T., \& Marcoulides, G. A. (2006). A first course in structural equation modeling. Lawrence Erlbaum Associates, Publishers: Mahwah, NJ.

Rigdon, E. E. (1995). A necessary and sufficient identification rule for structural models estimated in practice. Multivariate Behavioral Research, 30(3), 359-383.

Rogeberg, O., \& Elvik, R. (2016). The effects of cannabis intoxication on motor vehicle collision revisited and revised. Addiction, 111(8), 1348-1359. doi:10.1111/add.13347 
Romer, D., \& Hennessy, M. (2007). A Biosocial-Affect Model of Adolescent Sensation Seeking: The Role of Affect Evaluation and Peer-Group Influence in Adolescent Drug Use. Prevention Science, 8(2), 89-101.

Rosenberg, M. (1965). Society and the adolescent self-image. Princeton, NJ: Princeton University Press.

Ruedy, N. E., Moore, C., Gino, F., \& Schweitzer, M. E. (2013). The cheater's high: The unexpected affective benefits of unethical behavior. Journal of Personality and Social Psychology, 105(4), 531.

Schaefer, D. R., Haas, S. A., \& Bishop, N. J. (2012). A Dynamic Model of US Adolescents' Smoking and Friendship Networks. American Journal of Public Health, 102(6), e12-e18. doi:10.2105/AJPH.2012.300705

Schaefer, L. (2016). On the reinforcing nature of crime and punishment: An exploration of inmates' self-reported likelihood of reoffending. Journal of Offender Rehabilitation, 55(3), 168-194.

Schmitt, D. P., \& Allik, J. (2005). Simultaneous administration of the Rosenberg SelfEsteem Scale in 53 nations: exploring the universal and culture-specific features of global self-esteem. Journal of personality and social psychology, 89(4), 623 .

Schroeder, D. S., Laflin, M. T., \& Weis, D. L. (1993). Is There a Relationship between Self Esteem and Drug Use? Methodological and Statistical Limitations of the Research. Journal of drug issues, 23(4), 645-665.

Shivley, R., (2016). Marijuana legalization: Policy ahead of science. Journal of Community Corrections, 26(1), 9-11. 
Sigfúsdóttir, I. D., Thorlindsson, T., Kristjánsson, Á. L., Roe, K. M., \& Allegrante, J. P. (2009). Substance use prevention for adolescents: the Icelandic model. Health Promotion International, 24(1), 16-25.

Soole, D. W., Mazerolle, L., \& Rombouts, S. (2008). School-based drug prevention programs: A review of what works. Australian \& New Zealand Journal of Criminology, 41(2), 259-286.

Stevens, J., May, D., Rice, N., \& Jarjoura, G. R. (2011). Nonsocial Versus Social Reinforcers: Contrasting Theoretical Perspectives on Repetitive Serious Delinquency and Drug Use. Youth Violence \& Juvenile Justice, 9(4), 295-312. doi:10.1177/1541204011409764

Substance Abuse and Mental Health Services Administration. (2014). Results from the 2012 National Survey on Drug Use and Health: Summary of National Findings NSDUH Series H-48, HHS Publication No. (SMA) 14-4863. . Retrieved from Rockville, MD:

Temple, E. C., Brown, R. F., \& Hine, D. W. (2011). The 'grass ceiling': limitations in the literature hinder our understanding of cannabis use and its consequences. Addiction, 106(2), 238-244. doi:10.1111/j.1360-0443.2010.03139.x

Tobler, N. S., Roona, M. R., Ochshorn, P., Marshall, D. G., Streke, A. V., \& Stackpole, K. M. (2000). School-based adolescent drug prevention programs: 1998 metaanalysis. Journal of primary Prevention, 20(4), 275-336.

Triplett, R., \& Payne, B. (2004). Problem solving as reinforcement in adolescent drug use: Implications for theory and policy. Journal of Criminal Justice, 32(6), 617630. 
Trzesniewski, K. H., Donnellan, M. B., Moffitt, T. E., Robins, R. W., Poulton, R., \& Caspi, A. (2006). Low Self-Esteem During Adolescence Predicts Poor Health, Criminal Behavior, and Limited Economic Prospects During Adulthood. Developmental psychology, 42(2), 381-390. doi:10.1037/0012-1649.42.2.381

Vandenberg, R. J. (2002). Toward a further understanding of and improvement in measurement invariance methods and procedures. Organizational research methods, 5(2), 139-158.

Vandenberg, R. J., \& Lance, C. E. (2000). A review and synthesis of the measurement invariance literature: Suggestions, practices, and recommendations for organizational research. Organizational research methods, 3(1), 4-70.

Walker, D. D., Neighbors, C., Rodriguez, L. M., Stephens, R. S., \& Roffman, R. A. (2011). Social norms and self-efficacy among heavy using adolescent marijuana smokers. Psychology of Addictive Behaviors, 25(4), 727-732. doi:10.1037/a0024958

Whaley, R. B., Smith, J. M., \& Hayes-Smith, R. (2011). Teenage Drug and Alcohol Use: Comparing Individual and Contextual Effects. Deviant Behavior, 32(9), 818-845. doi:10.1080/01639625.2010.538351

Wichstrøm, T., \& Wichstrøm, L. (2009). Does sports participation during adolescence prevent later alcohol, tobacco and cannabis use? Addiction, 104(1), 138-149.

Wood, P. B., Cochran, J. K., Pfefferbaum, B., \& Arneklev, B. J. (1995). Sensationseeking and delinquent substance use: An extension of learning theory. Journal of drug issues, 25(1), 173-193. 
Wood, P. B., Gove, W. R., Wilson, J. A., \& Cochran, J. K. (1997). Nonsocial reinforcement and habitual criminal conduct: An extension of learning theory. Criminology, 35(2), 335-366.

Wood, P. B., Pfefferbaum, B., \& Arneklev, B. J. (1993). Risk-taking and self-control: Social psychological correlates of delinquency. Journal of Crime and Justice, 16(1), 111-130.

Yu, C. Y. (2002). Evaluating cutoff criteria of model fit indices for latent variable models with binary and continuous outcomes (Doctoral dissertation). University of California, Los Angeles, CA.

Yuan, K. H., \& Bentler, P. M. (2000). Three likelihood-based methods for mean and covariance structure analysis with nonnormal missing data. Sociological methodology, 30(1), 165-200.

Yuan, K. H., Bentler, P. M., \& Zhang, W. (2005). The effect of skewness and kurtosis on mean and covariance structure analysis: The univariate case and its multivariate implication. Sociological Methods \& Research, 34(2), 240-258.

Zhou, M. (2016). A Revisit of General Self-Efficacy Scale: Uni-or Multidimensional? Current Psychology, 35(3), 427-436.

Zimmerman, R. S., Cupp, P. K., Abadi, M., Donohew, R. L., Gray, C., Gordon, L., \& Grossl, A. B. (2014). The effects of framing and fear on ratings and impact of anti-marijuana PSAs. Substance Use \& Misuse, 49(7), 824-835. doi:10.3109/10826084.2014.880721 


\title{
CURRICULUM VITA
}

\author{
Heather Tolle \\ (502) 852-6567 \\ Department of Criminal Justice \\ University of Louisville \\ Brigman Hall 100I \\ Louisville, KY 40292 \\ heather.tolle@louisville.edu
}

\section{EDUCATION}

2017 (expected) Ph.D. University of Louisville- Criminal Justice

Dissertation title: "The sources of behavioral reinforcement: An examination of nonsocial reinforcement theory."

2007 M.A. University of Louisville- Psychology

2005 B.A. University of Louisville- Psychology

\section{RESEARCH POSITIONS}

2010- Present Research Manager,

NeuroRecovery Network

North American Clinical Trials Network (NACTN)

University of Louisville, Dept. of Neurological Surgery

2013-Present Data Manager and Analyst

"Examining the Prevalence and Correlates of PTSD and Quality of Life Issues among Kentucky Department of Corrections Staff." Funded by Kentucky Department of Corrections.

University of Louisville, Dept. of Criminal Justice

Faculty Supervisor: Dr. Kristin Swartz

2007-2007 Consultant Ethnographer

Smart Revenue, Louisville, KY

2006-2007 Early Intervention for Multi-risk Families Lab (Independent Study) University of Louisville Lab Director: Dr. Barbara Burns

2004-2005 Cognitive Decision Making Lab (Independent Study)

University of Louisville Lab Director: Dr. Stephen Edgell 


\section{PUBLICATIONS}

\section{PEER-REVIEWED JOURNAL ARTICLES}

Tolle, H. (in press). Gang Affiliation as a Measure of Social Structure in Social Structure Social Learning Theory. Deviant Behavior.

http://dx.doi.org/10.1080/01639625.2016.1206712

\section{TECHNICAL REPORTS}

Swartz, K., Roberts, A., \& Tolle, H. (2017). Examining the Prevalence and Correlates of PTSD among Kentucky Department of Corrections Staff. Submitted to Kentucky Department of Corrections.

Tolle, H., Harkema, S.J., Behrman, A.L., Schmidt-Read, M. (2016) NeuroRecovery Network Progress Report FY2015. Funding report submitted to the Christopher and Dana Reeve Foundation.

Tolle, H., Harkema, S.J., Behrman, A.L., Schmidt-Read, M. (2015) NeuroRecovery Network Progress Report FY2014. Funding report submitted to the Christopher and Dana Reeve Foundation.

Tolle, H., Harkema, S.J., Behrman, A.L., Schmidt-Read, M. (2014) NeuroRecovery Network Progress Report FY2013. Funding report submitted to the Christopher and Dana Reeve Foundation.

Tolle, H., Harkema, S.J., Behrman, A.L., Schmidt-Read, M. (2013) NeuroRecovery Network Progress Report FY2012. Funding report submitted to the Christopher and Dana Reeve Foundation.

Tolle, H., Harkema, S.J., Behrman, A.L., Schmidt-Read, M. (2012) NeuroRecovery Network Progress Report FY2011. Funding report submitted to the Christopher and Dana Reeve Foundation.

\section{WORK UNDER REVIEW}

Tolle, H., Ugiliweneza, B., Rapacz, A., Weintraub, B., Shogren, C., Gibson, J.L., Olson, J., Harkema, S.J \& Sharo, K. Impact of Community Fitness and Wellness Program on quality of life after a spinal cord injury. Under review at Disability and Rehabilitation.

Tolle, H., Rapacz, A., Weintraub, B., Shogren, C., Harkema, S. J., \& Gibson, J.L. Establishing the NeuroRecovery Network Community Fitness and Wellness Facilities: Multi-site fitness facilities provide activity-based interventions and assessments for evidence-based functional gains in neurologic disorders. Under review at Disability and Rehabilitation. 


\section{WORKS IN PROGRESS}

Tolle, H., \& Swartz, K. Factors buffering correctional officers from burnout.

Tolle, H. \& Nelson, N. T. The social structure social learning impact of legalization of marijuana on youth marijuana use.

\section{PRESENTATIONS}

Tolle, H, Swartz, K. \& French, A.T. (November 2016) Burnout, Turnover, Corruption, and Willingness to Report Wrong-doing Among Correctional Staff. American Society of Criminology. New Orleans, LA.

Tolle, H. (March 2016) Examining Interaction Effects of Gang Involvement on Social Learning Theory and Deviance. Academy of Criminal Justice Sciences. Denver, CO.

Swartz, K., French, A. \& Tolle, H. (March 2016). PTSD among correctional staff: A preliminary analysis. Academy of Criminal Justice Sciences. Denver, CO.

Tolle, H. \& Andreescu, V. (November 2015) An exploratory analysis of women's intrasexual lethal aggression. American Society of Criminology. Washington DC.

Tolle, H \& McCord, E.S. (November 2015) Mapping in criminology and criminal justice. University of Louisville Geographic Information Systems (GIS) Day. Louisville, KY

Tolle, H. (April 2013) NRN Data Reporting Review. NeuroRecovery Network National Summit Data Managers Meeting. Louisville, KY.

Tolle, H. (April 2012) Advanced Data Entry Techniques. NeuroRecovery Network National Summit Data Managers Meeting. Louisville, KY.

Tolle, H. (April 2011) Data Entry in the NRN. NeuroRecovery Network National Summit Data Managers Meeting. Louisville, KY.

\section{POSTER PRESENTATIONS}

Gallahar, A., Tolle, H. \& Harkema, S.J. (September 2016) Benefits of Community Fitness and Wellness Programs and Significance in the Continuum of Care for Spinal Cord Injury Populations. Academy of Spinal Cord Injury Professionals (ASCIP). Nashville, TN.

\section{TEACHING EXPERIENCE}

Courses taught - Department of Criminal Justice, University of Louisville Undergraduate

Research Methods (Spring 2017)

\section{MEMBERSHIP IN PROFESSIONAL ORGANIZATIONS}

American Society of Criminology 
Academy of Criminal Justice Sciences

WORKSHOPS

Grant Writing academy

Publishing academy

STEM teaching academy

\section{CERTIFICATIONS}

Collaborative IRB Training Initiative (CITI)

Health Insurance Portability and Accountability Act (HIPAA) 